\title{
A Comparison of the Effects of an Upper-Level Anticyclone and a Lower-Level Cyclone on Tropical Cyclogenesis in Idealized Simulations
}

\author{
Xi CAO \\ Center for Monsoon System Research, Institute of Atmospheric Physics, Chinese Academy of Sciences, China \\ State Key Laboratory of Severe Weather, Chinese Academy of Meteorological Sciences, China \\ Shanghai Typhoon Institute, China Meteorological Administration, China \\ Renguang WU \\ School of Earth Sciences, Zhejiang University, Hangzhou, China \\ Center for Monsoon System Research, Institute of Atmospheric Physics, Chinese Academy of Sciences, China \\ Yifeng DAI \\ Tongji Zhejiang College, China \\ and
}

Jing XU

State Key Laboratory of Severe Weather, Chinese Academy of Meteorological Sciences, China

(Manuscript received 6 November 2019, in final form 8 June 2020)

\begin{abstract}
This study examined the effects of an upper-level anticyclonic circulation and a lower-level cyclonic circulation on tropical cyclone (TC) genesis. We ran idealized simulations using the Advanced Research Weather Research and Forecasting (WRF-ARW) model. The simulation results show that the upper-level anticyclonic circulation makes a negative contribution to TC genesis, while the lower-level cyclonic circulation makes a positive contribution. The upper-level anticyclonic circulation results in slower TC genesis due to a substantial vertical zonal wind shear that shifts the upper-level vortex eastward from its initial position. This shift is unfavorable for the vortex's vertical alignment and warm core maintenance. This substantial vertical zonal wind shear is associated with the asymmetric vertical motion and associated diabatic heating, induced by the lower-level beta gyre. The upper-level anticyclonic circulation increases the westerly wind north of the vortex, resulting in a substantial vertical westerly wind shear. Thus, the initial upper-level anticyclonic circulation is unnecessary for TC genesis. The strong upper-level anticyclonic circulation, generally observed with a strong TC, should be considered a result of deep convection. The strong lower-level winds induce large surface heat fluxes and vorticity due to the superposition of the large-scale lower-level cyclonic circulation and vortex. These conditions lead to strengthened convection and diabatic heating and a quick build-up of positive vorticity, resulting in rapid TC genesis.
\end{abstract}

Keywords upper-level anticyclonic circulation; lower-level cyclonic circulation; idealized simulation; tropical cyclone genesis

Corresponding author: Xi Cao, Building 40, Huayanli, Bei-

chen West Road, Chaoyang District, Beijing 100029, China

E-mail: caoxi09@mail.iap.ac.cn

J-stage Advance Published Date: 9 July 2020

(C) The Author(s) 2020. This is an open access article published by the Meteorological Society of Japan under a Creative Commons Attribution 4.0 International (CC BY 4.0) license (https://creativecommons.org/licenses/by/4.0). 
Citation Cao, X., R. Wu, Y. Dai, and J. Xu, 2020: A comparison of the effects of an upper-level anticyclone and a lower-level cyclone on tropical cyclogenesis in idealized simulations. J. Meteor. Soc. Japan, 98, 1005-1027, doi:10.2151/jmsj.2020-052.

\section{Introduction}

Tropical cyclone (TC) genesis is characterized by the transformation of a random cumulus-scale convective system into a self-sustaining synoptic-scale cyclonic system with a warm core under favorable largescale conditions. How a weak tropical disturbance intensifies within a synoptic-scale environment has intrigued researchers for decades. Some observational studies have focused on how upper-level circulation affects TC intensification. Merrill (1988) suggested that, when one or two outflow channels exist at the upper-level, TCs intensify at a quick rate during the Atlantic storm season. The TCs generally intensify at a slow speed when there is a closed circulation without an outflow channel because they are unable to ventilate mass in the outflow layer. On the other hand, TC intensification can also be linked to a tropical upper tropospheric trough, which is favorable for vigorous convection in the inner core (Sadler 1976; Holland and Merrill 1984).

In addition to external environments at the upperlevel, Wang (1998, hereafter W98) studied the influence of the vortex's vertical structure on TC intensification using an idealized model. W98 suggested that a vortex with a maximum tangential wind of 30 $\mathrm{m} \mathrm{s}^{-1}$ without an upper-level anticyclone can intensify at a more rapid rate than a vortex with an upper-level anticyclone. However, there is a lack of detailed analyses on the relative importance of an upper-level anticyclonic circulation and a lower-level cyclonic circulation in TC genesis. Although there are many observational and numerical studies of the relationship between upper-level circulation and TC intensification (Holland and Merrill 1984; DeMaria et al. 1993; Rappin et al. 2011; Leroux et al. 2013), there is relatively little research on the relationship between upper-level conditions and TC genesis.

In an observational study, McBride and Zehr (1981, hereafter MZ81) found that developing cloud clusters generally exhibit enhanced lower-level positive vorticity, near-zero vertical wind shear over the vortex center, vertical westerly wind shear to the north, and vertical easterly wind shear to the south. This vertical zonal wind shear pattern implies that both a largescale upper-level anticyclonic circulation and a large- scale lower-level cyclonic circulation are favorable for TC genesis (Gray 1968, 1998). However, another hypothesis is that a compensating upper-level anticyclonic circulation must develop due to the convergence of moisture and the release of latent heat by deep convection. Therefore, further investigation is required to understand whether an upper-level anticyclonic circulation is necessary for TC genesis.

In addition to upper-level anticyclonic circulation, most observational studies have indicated that lowerlevel circulation plays an essential role in TC genesis (Gray 1968; MZ81; Ritchie and Holland 1999; Lee et al. 2008; Wu et al. 2013; Feng et al. 2014; Cao et al. 2016, 2018, 2020; Cao and Wu 2018a, b). For example, Ritchie and Holland (1999) identified several typical circulation patterns associated with TC formation over the western North Pacific (WNP), including monsoon shear lines, monsoon confluence zones, and monsoon gyres. Wu et al. (2013) examined monsoon gyre activity, structures, and the related creation of TCs using 11-year reanalysis data. The identified 31 monsoon gyres accompanied by $43 \mathrm{TCs}$, accounting for $20.3 \%$ of the total number of TCs during the TC season over the WNP. Recent modeling studies from Cao et al. (2014a, hereafter C14; 2014b) demonstrated that the intraseasonal oscillation and interannual variation of the monsoon trough exert strong controls on TC formation through both dynamic (vorticity and convergence) and thermodynamic (moisture) effects over the WNP. Although most of these studies were observational, it is unclear whether TC genesis facilitated by the lower-level circulation can be confirmed through idealized simulations in a full-physics model. Recently, some studies (Xu et al. 2016; Yan et al. 2019) found that a TC does not form and intensify rapidly when it is embedded within a monsoon gyre, which contradicts the observational studies.

Based on previous studies, the following intriguing questions arise: Are the upper-level anticyclonic circulation and lower-level cyclonic circulation equally favorable for TC genesis? How do the upper-level anticyclonic circulation and the lower-level cyclonic circulation play roles in TC genesis? This work attempts to answer these questions through a series of idealized simulations using a mesoscale model.

The remainder of this paper is organized as follows. 
Section 2 provides the model and experimental design. Section 3 describes the time evolutions of vortices, examines the mechanisms by which the upper-level anticyclonic circulation and lower-level cyclonic circulation impact TC formation, and discusses the sensitivity of vortex development to different structures of the upper-level anticyclonic circulation and initial conditions with lower-level cyclonic circulation included in additional experiments. Finally, Section 4 presents a summary and a short discussion.

\section{Model and experimental designs}

\subsection{Model}

Our results are based on three major idealized numerical experiments, performed using the nonhydrostatic Advanced Research Weather Research and Forecasting (WRF-ARW; Skamarock et al. 2008) model (version 3.3.1). The model is triply nested with two-way interaction and fixed inner domains. The mesh sizes in the three domains are $241 \times 241,241$ $\times 241$, and $481 \times 481$, with horizontal grid sizes of 27,9 , and $3 \mathrm{~km}$, respectively. There are 35 levels in the vertical direction from the surface to $10 \mathrm{hPa}$. The Kain-Fritch convective scheme is applied to the two outer meshes (Kain and Fritsch 1993), and an explicit microphysics scheme (Lin et al. 1983) is used in all meshes. The model experiments are integrated to 120 $\mathrm{h}$. The model is set on a beta plane at $15^{\circ} \mathrm{N}$. In the control experiment, the background environmental flow is quiescent, and a constant sea surface temperature (SST) of $29^{\circ} \mathrm{C}$ is specified. The relative humidity and other thermodynamic variables are horizontally homogeneous, based on mean observations at Willis Island in January (Holland 1997). The other model settings are identical to those illustrated in C14.

\subsection{Experimental designs}

The experiments are initialized with the same axisymmetric weak vortex. The maximum tangential wind of the vortex is $8 \mathrm{~m} \mathrm{~s}^{-1}$ at a radius of $150 \mathrm{~km}$ at the surface with the vertical profile of a sine function using the sigma vertical coordinate (Wang 1995). Also, an axisymmetric upper-level anticyclonic circulation and a lower-level cyclonic circulation are inserted into the background fields. The insertion facilitated examining the impacts of large-scale circulation on vortex development. The initial maximum tangential winds of the upper- and lower-level circulations are both $8 \mathrm{~m} \mathrm{~s}^{-1}$ at a radius of $700 \mathrm{~km}$ from the circulation centers. Both circulations have vertical profiles following a sine function. The upper-level anticyclonic circulation reaches its maximum intensity at $150 \mathrm{hPa}$; then, the intensity decreases both upward to zero at $100 \mathrm{hPa}$ and downward to zero at $300 \mathrm{hPa}$. The lowerlevel cyclonic circulation has a maximum intensity at the sea surface and gradually decreases upward to zero at $300 \mathrm{hPa}$. Given the wind fields, the mass and thermodynamic fields are derived based on a nonlinear balance equation so that the initial vortex, upper-level anticyclonic circulation, and lower-level cyclonic circulation all satisfy the hydrostatic and gradient wind balances (Wang 1995). There is no apparent difference in the initial relative humidity around the cores of the vortices as a result of the balancing procedure (figure not shown). The upper-level anticyclonic circulation and lower-level cyclonic circulation are the background fields for the development of the initial vortex, not the vortex's vertical structure.

The horizontal structure of the lower-level cyclonic circulation is similar to the lower-level component of a composite monsoon gyre (Wu et al. 2013). Note that this lower-level cyclonic circulation is not a monsoon gyre. A typical monsoon gyre has a baroclinic vertical structure, which includes both the lower-level and the upper-level circulations ( $\mathrm{Wu}$ et al. 2013; Yan et al. 2019). Furthermore, according to reanalysis data (see Fig. 2 of C14), the vertical structures of the upperlevel anticyclonic circulation and lower-level cyclonic circulation are consistent with the tangential wind's vertical structure during the active phase of the intraseasonal oscillation of the monsoon trough over the WNP. During the active phase of the monsoon trough's intraseasonal oscillation, the tangential wind is characterized by a typical baroclinic structure. This structure consists of an upper-level anticyclonic circulation above $300 \mathrm{hPa}$ and a lower-level cyclonic circulation below $300 \mathrm{hPa}$.

The effects of the upper-level anticyclonic circulation and lower-level cyclonic circulation on TC genesis are studied by performing four experiments and comparing their results. In the control experiment (hereafter CTL), an initial weak vortex is placed in a resting environment. In one sensitivity experiment (hereafter SUA), the upper-level anticyclonic circulation is added to CTL as the background field of vortex development. In the second sensitivity experiment (hereafter SLC), we conduct the simulation in the same way except the lower-level cyclonic circulation is added to CTL. In the third sensitivity experiment (hereafter SUALC), we include both the upper-level anticyclonic circulation and the lower-level cyclonic circulation. Four additional experiments were performed for further comparison to examine the potential influences of different structures of the upper-level 
Table 1. Model experiment descriptions. "S" denotes a sensitivity experiment.

\begin{tabular}{|c|c|}
\hline Experiment name & Description \\
\hline CTL & $\begin{array}{l}\text { Initial vortex with a maximum tangential wind of } 8 \mathrm{~m} \mathrm{~s}^{-1} \text { at a radius of } 150 \mathrm{~km} \text { at the surface with the } \\
\text { vertical profile of a sine function in a resting environment }\end{array}$ \\
\hline SUA & $\begin{array}{l}\text { Similar to CTL except with a strong upper-level anticyclonic circulation with a maximum tangential } \\
\text { wind of } 8 \mathrm{~m} \mathrm{~s}^{-1} \text { at a radius of } 700 \mathrm{~km} \text { at } 150 \mathrm{hPa}\end{array}$ \\
\hline SLC & $\begin{array}{l}\text { Similar to CTL except with a strong lower-level cyclonic circulation with a maximum tangential wind } \\
\text { of } 8 \mathrm{~m} \mathrm{~s}^{-1} \text { at a radius of } 700 \mathrm{~km} \text { at the surface }\end{array}$ \\
\hline SUALC & $\begin{array}{l}\text { Similar to CTL except with both a lower-level cyclonic circulation and an upper-level anticyclonic } \\
\text { circulation }\end{array}$ \\
\hline $\mathrm{CTL}_{-} \mathrm{f}$ & Similar to CTL except on an f plane \\
\hline SUA_f & Similar to SUA except on an $\mathrm{f}$ plane \\
\hline SUAdry50 & Similar to SUA except that the initial specific humidity is decreased by $50 \%$ \\
\hline SUA_P250 & $\begin{array}{l}\text { Similar to SUA except for the maximum tangential wind of the upper-level anticyclonic circulation } \\
\text { being at } 250 \mathrm{hPa}\end{array}$ \\
\hline SUA_P100 & $\begin{array}{l}\text { Similar to SUA except for the maximum tangential wind of the upper-level anticyclonic circulation } \\
\text { being at } 100 \mathrm{hPa}\end{array}$ \\
\hline SUA_R400 & $\begin{array}{l}\text { Similar to SUA except for the maximum tangential wind of the upper-level anticyclonic circulation } \\
\text { being at a radius of } 400 \mathrm{~km}\end{array}$ \\
\hline SUA_V16 & $\begin{array}{l}\text { Similar to SUA except for the upper-level anticyclonic circulation having a maximum tangential wind } \\
\text { of } 16 \mathrm{~m} \mathrm{~s}^{-1}\end{array}$ \\
\hline
\end{tabular}

anticyclonic circulation on TC genesis. These additional experiments involve modifying three parameters: 1) the height of the maximum upper-level anticyclonic circulation, 2) the radius of the maximum anticyclonic wind, and 3) the magnitude of the maximum anticyclonic wind. Table 1 provides the details of the model experiments.

Figure 1 shows the initial wind fields at $150 \mathrm{hPa}$ and $850 \mathrm{hPa}$ and the vertical-radial cross-section of the tangential wind of the vortex in the CTL, SUA, and SLC experiments. The upper-level anticyclone is stronger in SUA than in CTL and SLC (Figs. 1a-c), and the lower-level cyclone is stronger in SLC than in CTL and SUA (Figs. 1d-f). Furthermore, the tangential wind at the vortex surface is stronger outside of the maximum wind radius in SLC than in CTL and SUA (Figs. 1g-i).

\section{Mechanism of impacts}

\subsection{Evolutions of the vortices}

Figure 2 shows the time evolutions of the minimum sea level pressure (MSLP) and maximum azimuthal-mean wind (MAMW) at the height of $10 \mathrm{~m}$ in CTL, SUA, SLC, and SUALC from the 3-km simulation data. The vortices in the first $60 \mathrm{~h}$ experience adjustment and spin-up processes, with little development, followed by different intensification rates among the four cases. The development of vortices varies with the existing background flows on a beta plane. A strong TC develops at $t=120 \mathrm{~h}$ in SLC with an MSLP of $959 \mathrm{hPa}$, whereas the vortex develops much more slowly throughout the whole 120 -h simulation in SUA with an MSLP of $994 \mathrm{hPa}$. The vortices in CTL and SUALC develop at rates between those in SLC and SUA with final MSLPs of $980 \mathrm{hPa}$ and $967 \mathrm{hPa}$, respectively. The time when the MAMW at $10 \mathrm{~m}$ exceeds $15 \mathrm{~m} \mathrm{~s}^{-1}$ is defined as the time of cyclogenesis. This definition may correspond to a peak wind above $17 \mathrm{~m} \mathrm{~s}^{-1}$, but denotes a relatively stable vortex. Based on this definition, tropical cyclogenesis occurs at $t=$ $99 \mathrm{~h}$ in CTL and SUALC, at $t=117 \mathrm{~h}$ in SUA, and at $t=93 \mathrm{~h}$ in SLC.

Also, the simulated TCs have a vertical structure typical of a strong TC at the end of the simulation. Figure 3 displays the vertical-radial cross-sections of the azimuthal-mean tangential wind, radial wind, and diabatic heating fields in CTL, SUA, and SLC. The TCs in these three experiments are all characterized by a tilted eyewall and a salient "in-up-out" secondary circulation. In SLC, the maximum tangential wind reaches $58 \mathrm{~m} \mathrm{~s}^{-1}$ at a radius of nearly $40 \mathrm{~km}$ at 850 $\mathrm{hPa}$ (Fig. 3c). Furthermore, there are strong radial inflow and outflow layers in the planetary boundary layer (PBL) and upper-level, respectively (Fig. 3f). 

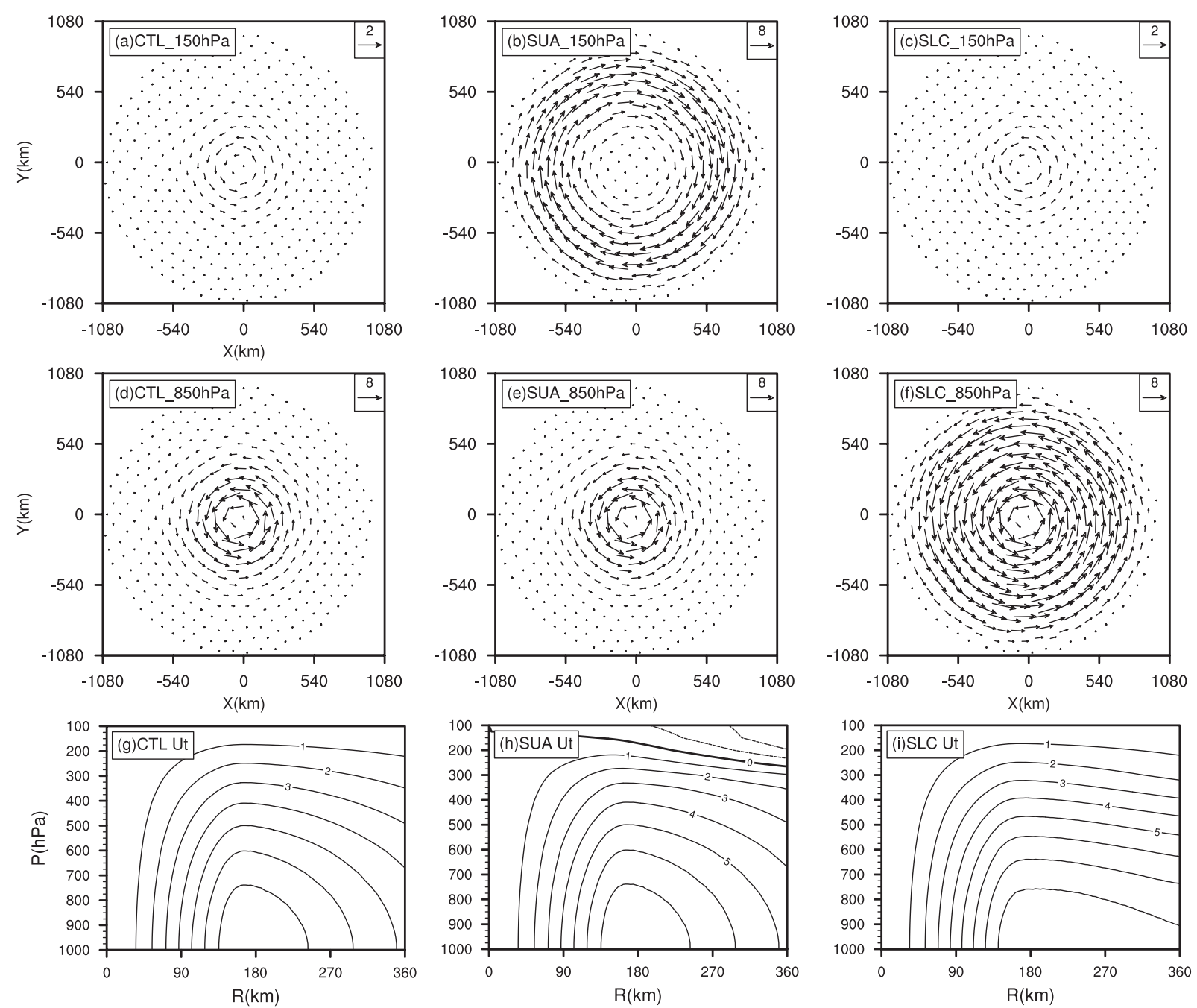

Fig. 1. The (a-c) 150-hPa and (d-f) 850-hPa wind fields (vectors) of the initial vortices in (a, d) CTL, (b, e) SUA and (c, f) SLC. Vertical-radial cross-sections of the azimuthal-mean tangential wind $\left(\mathrm{m} \mathrm{s}^{-1}\right)$ for the initial vortices in (g) CTL, (h) SUA, and (i) SLC.

The structures of the axisymmetric TC wind and heating fields in CTL and SUA are similar to those in SLC but with apparently weak magnitudes (Figs. 3a, b, $\mathrm{d}, \mathrm{e})$.

The modeling results indicate that the vortex with the enhanced lower-level cyclonic circulation has a rapid intensification rate. This finding is partly consistent with previous observational and numerical analyses insomuch that a preexisting weak disturbance in an environment with enhanced lower-level cyclonic vorticity is more likely to evolve into a TC (Gray 1968, 1998; Zehr 1992; Cao et al. 2012, 2014a, b; Fu et al. 2012). However, Xu et al. (2016) showed that a vortex does not always experience rapid development when it interacts with a monsoon gyre. The discrepancy between the findings of this study and $\mathrm{Xu}$ et al. (2016) are discussed further in the following section.

On the other hand, the upper-level anticyclonic circulation makes a negative contribution to vortex development compared to CTL. This result is inconsistent with the earlier study of MZ81, which reported that the presence of an upper-level anticyclonic circulation is necessary and favorable for TC genesis. However, our finding is consistent with the argument in W98: During the vortex intensification stage, a vortex without an upper-level anticyclonic circulation develops more quickly than a vortex with an upperlevel anticyclonic circulation. We will further investi- 

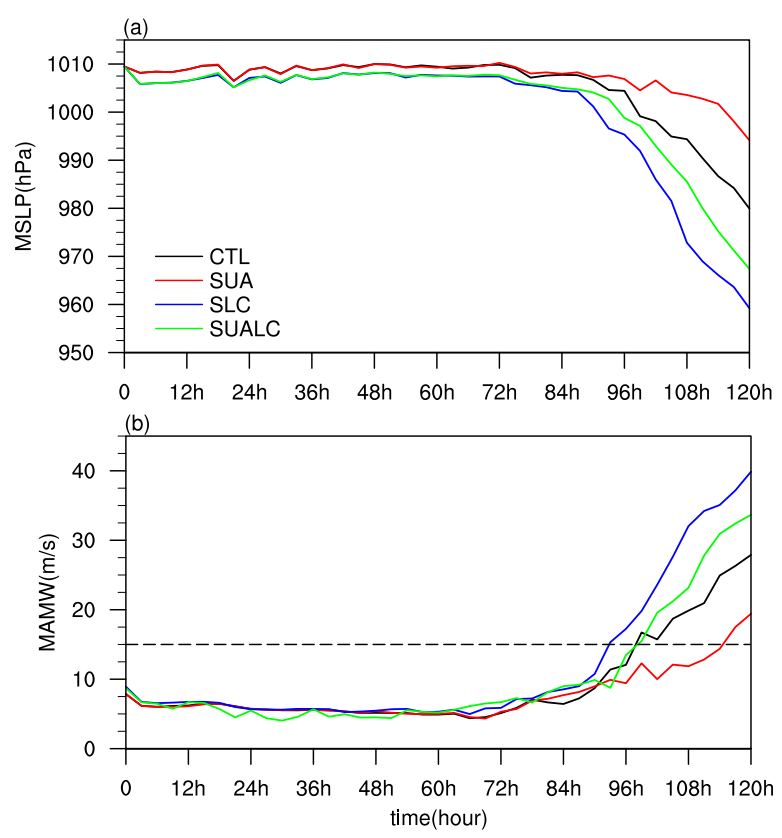

Fig. 2. The time evolutions of (a) the MSLP (hPa) and (b) the MAMW speed $\left(\mathrm{m} \mathrm{s}^{-1}\right)$ at the $10 \mathrm{~m}$ height in four experiments CTL (black), SUA (red), SLC (blue), and SUALC (green). The abscissa represents time (hour), and while the ordinate corresponds to the value of intensity. The dashed line in (b) denotes the TC genesis time when the MAMW speed exceeds $15 \mathrm{~m} \mathrm{~s}^{-1}$.

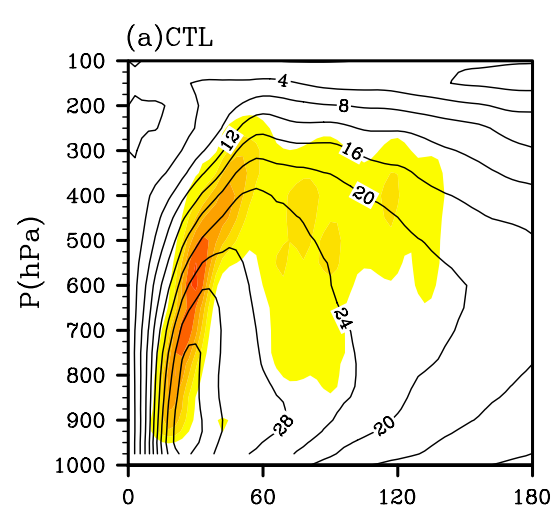

(d)

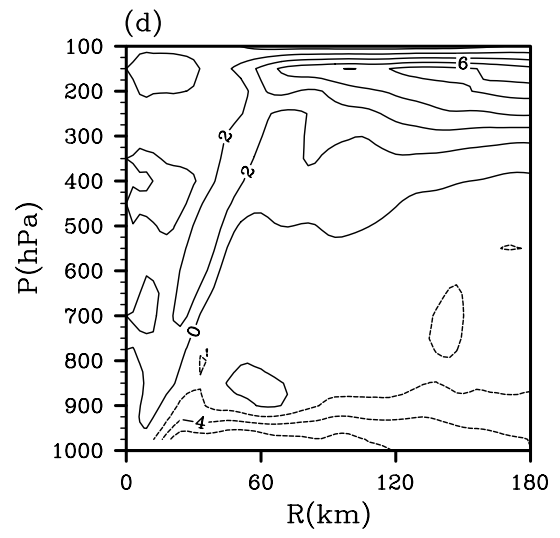

(b)SUA

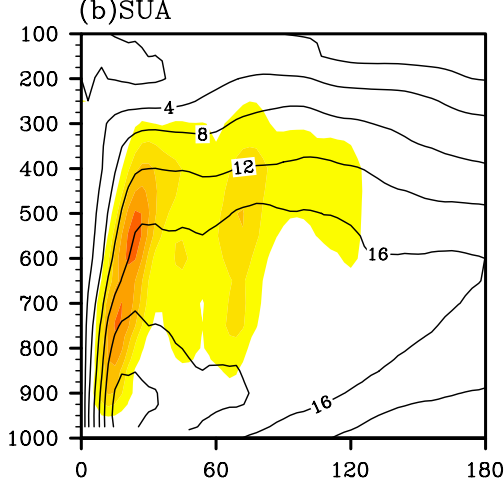

(e)

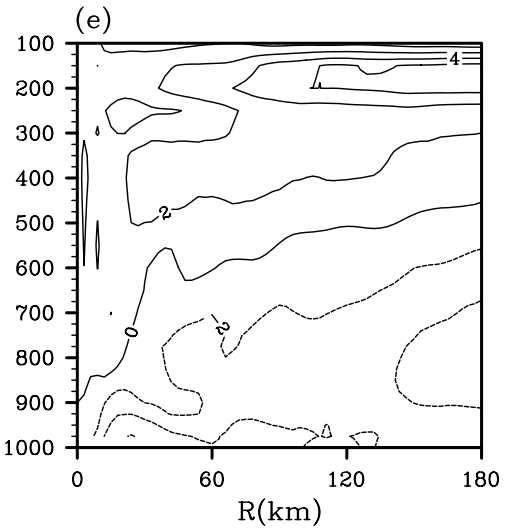

(c)SLC

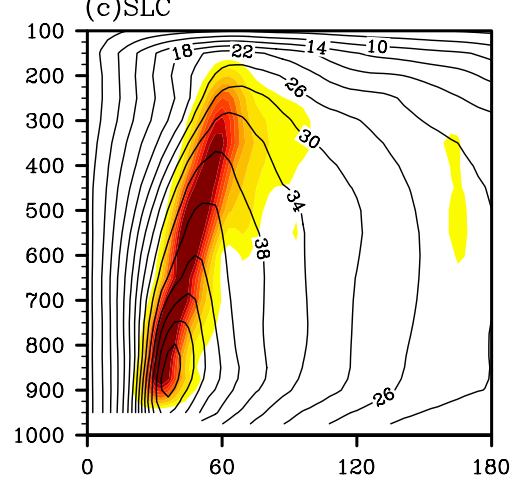

(f)

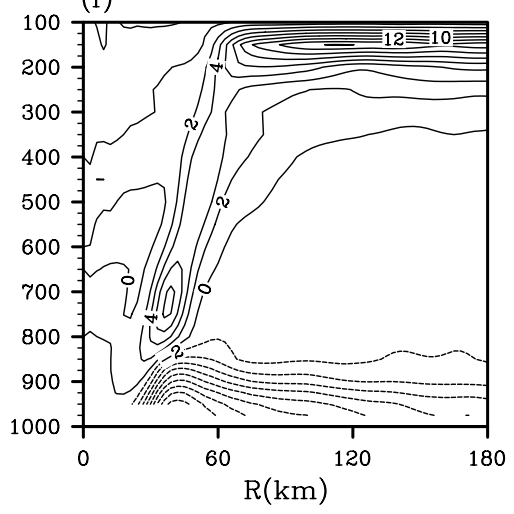

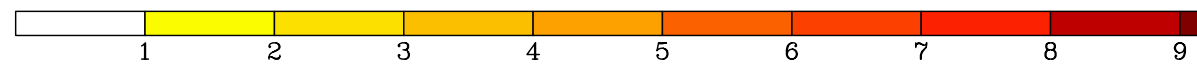

Fig. 3. The vertical-radial cross-sections of the azimuthal-mean tangential wind (contours, $\mathrm{m} \mathrm{s}^{-1}$ ) and diabatic heating (shaded, $10^{-3} \mathrm{~K} \mathrm{~s}^{-1}$ ) in (a) CTL, (b) SUA), and (c) SLC at $t=120 \mathrm{~h}$. (d-f) The same as in Figs. 3a-c except for the radial wind (contours, $\mathrm{m} \mathrm{s}^{-1}$ ). 

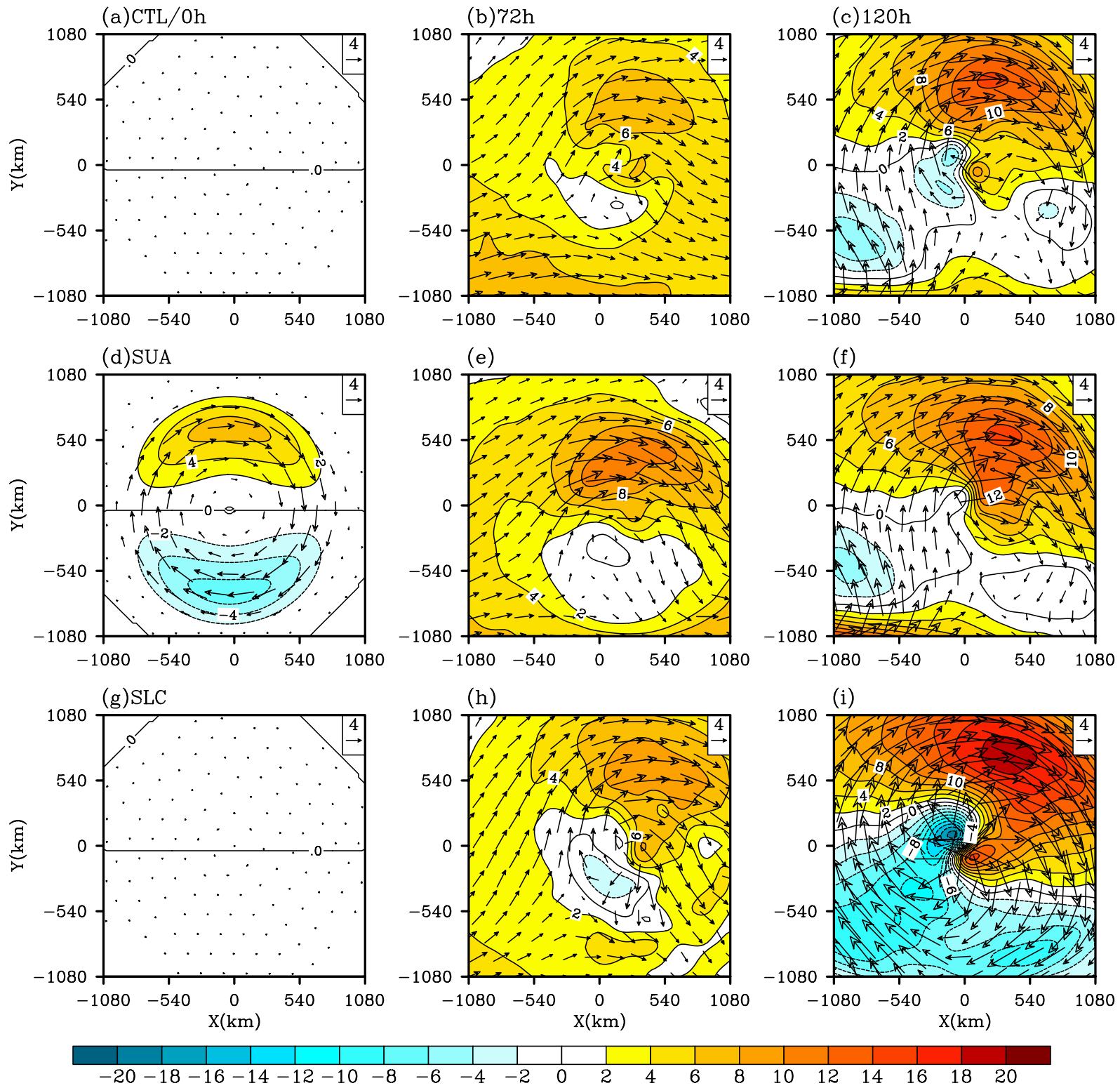

Fig. 4. The wind vectors and zonal velocities (shaded) at $150 \mathrm{hPa}$ in (a-c) CTL, (d-f) SUA, and (g-i) SLC at $t=$ $0 \mathrm{~h}$ (left), $72 \mathrm{~h}$ (middle), and $120 \mathrm{~h}$ (right) from the $27 \mathrm{~km}$ simulation.

gate why the upper-level anticyclonic circulation and lower-level cyclonic circulation have opposite effects on TC genesis in the following analyses.

\subsection{Upper-level anticyclonic circulation}

Figure 4 shows the wind field and zonal wind evolutions at $150 \mathrm{hPa}$ in CTL, SUA, and SLC from the 27-km simulation data at $t=0 \mathrm{~h}, 72 \mathrm{~h}$, and $120 \mathrm{~h}$. At first, the winds at $150 \mathrm{hPa}$ in CTL and SLC are negligible, whereas a strong anticyclonic circulation appears in SUA (Figs. 4a, d, g). At $t=72 \mathrm{~h}$, westerly winds almost prevail at the upper-level in CTL and SUA. The stronger winds appear north of the vortex center in the latter (Figs. 4b, e). This result implies there are westerly winds in the upper-level of SUA, induced by the large-scale background circulation, resulting in large vertical wind shear. In contrast, a relatively clear anticyclonic circulation develops, with weak easterly winds located on the southwest side of the vortex center in SLC (Fig. 4h). Toward the end of 

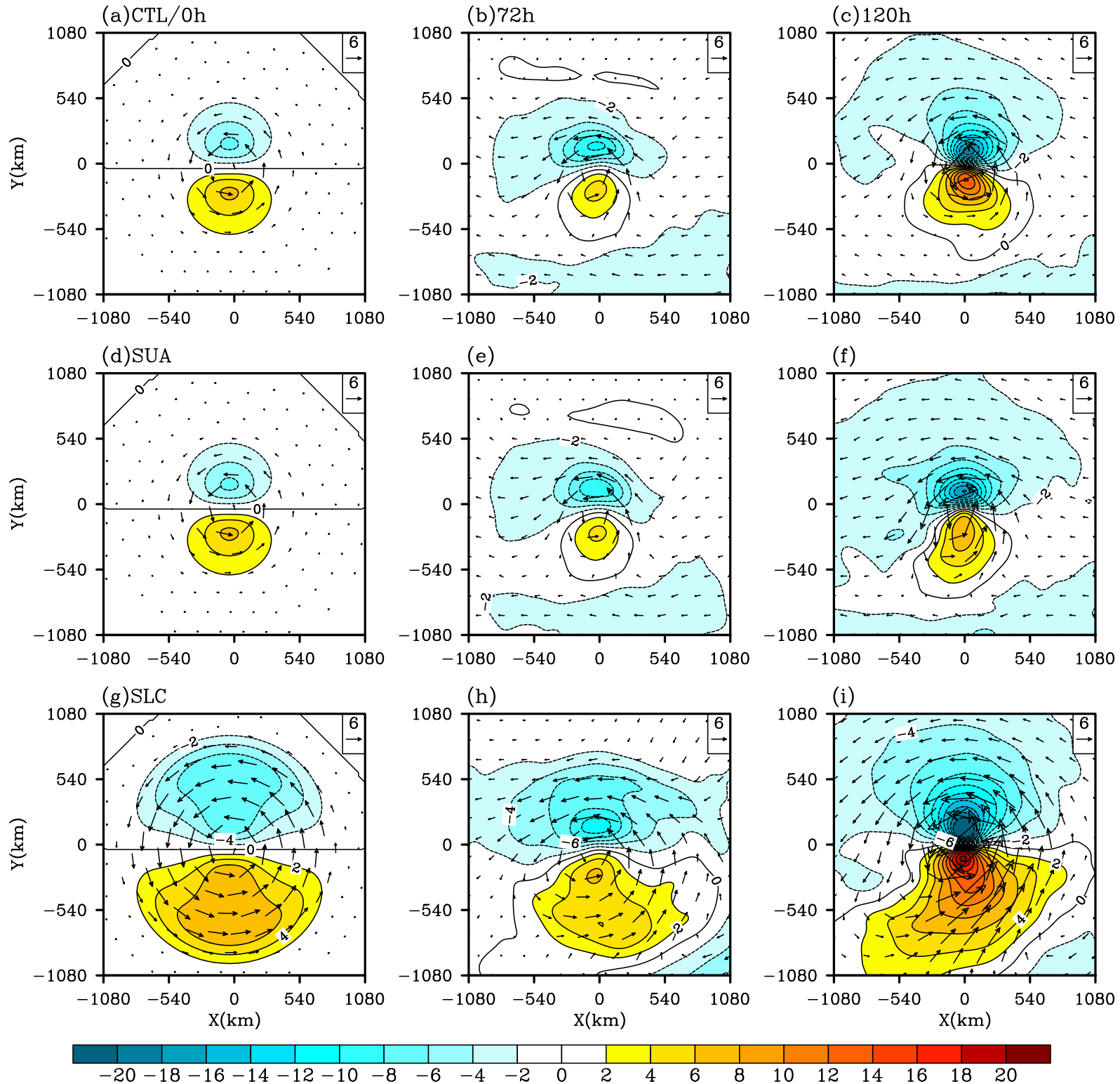

Fig. 5. The same as in Fig. 4 but at $850 \mathrm{hPa}$.

the simulation, the westerly winds on the north side of the vortex center intensify from $6 \mathrm{~m} \mathrm{~s}^{-1}$ to $14 \mathrm{~m} \mathrm{~s}^{-1}$ in CTL (Figs. 4b, c) and from $10 \mathrm{~m} \mathrm{~s}^{-1}$ to $14 \mathrm{~m} \mathrm{~s}^{-1}$ in SUA (Figs. 4e, f). Furthermore, there is apparent divergence around the vortex center, with easterly winds to the west and westerly winds to the east in CTL (Fig. 4c), while strong westerly winds are still dominant to the northeast in SUA (Fig. 4f). In the presence of the lower-level cyclonic circulation, a rather strong and organized anticyclonic circulation appears in SLC (Fig. 4i). This circulation implies that the upper-level anticyclonic circulation develops well due to well-organized deep convection.

In addition to the upper-level winds, we also examined the winds at the lower-level (Fig. 5). Initially, the winds of the vortices are the same in CTL and SUA at $850 \mathrm{hPa}$ (Figs. 5a, d), whereas the winds in SLC spread widely over a large area (Fig. $5 \mathrm{~g}$ ). At $t=72 \mathrm{~h}$, although the extents of the vortices in CTL and SUA are almost the same, the wind magnitude is slightly larger in CTL than in SUA; this indicates that the upper-level anticyclonic circulation has an overall 
negative effect on vortex development (Figs. 5b, e). On the other hand, the wind magnitudes are almost the same in CTL and SLC, with a maximum easterly wind of $10 \mathrm{~m} \mathrm{~s}^{-1}$ (Figs. 5b, h). However, the extents of the easterly and westerly winds are broader in SLC than in CTL and SUA. At $t=120 \mathrm{~h}$, the winds are much stronger in SLC than in CTL and SUA (Figs. 5c, f, i).

Based on the upper-level wind distributions in Fig. 4, Fig. 6 further shows the area-averaged $(720 \mathrm{~km} \times$ $720 \mathrm{~km}$ ) vertical zonal wind shear, which dominates the total vertical wind shear, around the TC center between $150 \mathrm{hPa}$ and $850 \mathrm{hPa}$ from $t=0 \mathrm{~h}$ to $t=96$ h. Note that $200 \mathrm{hPa}$ and $850 \mathrm{hPa}$ are conventional choices for calculating the vertical wind shear. However, in the present study, the upper-level circulation is maximal at $150 \mathrm{hPa}$. To better examine the background vertical wind shear's effect on TC genesis, a spatial filtering technique is applied to separate the mesoscale vortex from the environmental circulation. Winds with wavelengths larger than $500 \mathrm{~km}$ are considered large-scale background circulation, while winds with wavelengths smaller than $500 \mathrm{~km}$ represent the TC-scale vortex and smaller-scale convection. A strong vertical wind shear can inhibit TC development by ventilating moisture and energy away from the TC core region (e.g., Gray 1968), or entraining low-entropy air into the boundary layer (e.g., Riemer et al. 2010). The differences in the vertical zonal wind shear are closely associated with the development of vortices in these three experiments. The vertical zonal wind shear in SUA ranges from $6 \mathrm{~m} \mathrm{~s}^{-1}$ to $8 \mathrm{~m} \mathrm{~s}^{-1}$ after $t=66 \mathrm{~h}$, whereas it varies between $-2 \mathrm{~m} \mathrm{~s}^{-1}$ and $4 \mathrm{~m} \mathrm{~s}^{-1}$ in SLC, and the vertical zonal wind shear in CTL falls between $0 \mathrm{~m} \mathrm{~s}^{-1}$ and $6 \mathrm{~m} \mathrm{~s}^{-1}$. Before $t=$ $72 \mathrm{~h}$, the vertical zonal wind shears in the three runs have prominent differences before the vortices start to intensify (Figs. 6, 2). Note that the difference in the vertical zonal wind shear is not very sensitive to the size of the averaging box (such as $720 \mathrm{~km} \times 720 \mathrm{~km}$, $600 \mathrm{~km} \times 600 \mathrm{~km}$, and $450 \mathrm{~km} \times 450 \mathrm{~km})$ or to the use of spatial filtering (figures not shown).

The evolution of the vertical zonal wind shear depends closely on the zonal wind structures at the upper and lower levels, particularly the former. At first, the upper-level anticyclonic circulation is antisymmetric around the vortex center (Fig. 4d). At $t=72 \mathrm{~h}$, the westerly winds to the north in SUA are the strongest among the three experiments at the upper-level (Fig. $4 \mathrm{e}$ ); these westerly winds are associated with the development of a beta gyre in the lower-level cyclonic circulation and the resultant asymmetry. A cyclonic circulation-induced beta gyre is a pair of vorticity

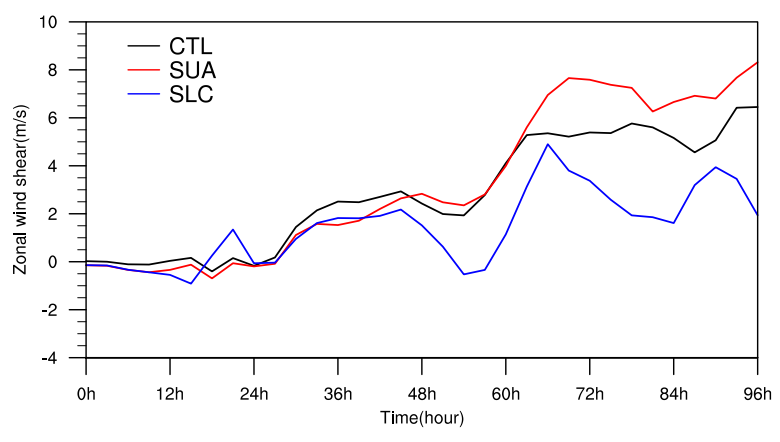

Fig. 6. The area-averaged $(720 \mathrm{~km} \times 720 \mathrm{~km})$ vertical zonal wind shear $(150-850 \mathrm{hPa})$ of CTL (black), SUA (red), and SLC (blue) from $t=0 \mathrm{~h}$ to $t=96 \mathrm{~h}$.

anomalies, with low vorticity to the northeast of the cyclone center and high vorticity to the southwest of the cyclone center at the lower-level. These conditions lead to maximum winds in the northeastern part of the vortex at the lower-level (Holland 1983; Fiorino and Elsberry 1989; Wu and Emanuel 1993, 1994). The strong winds in the northeastern quadrant of the vortex induce large surface heat fluxes (including sensible and latent heat fluxes) and thus higher atmospheric humidity (figure not shown). The friction-induced near-surface inflow further leads to ascending motion and more upward moisture transport, facilitating more convective heating in the region with the maximum wind and heat fluxes.

Figure 7 shows the $600-\mathrm{hPa}$ geopotential height, sea level pressure (SLP), and 300-hPa vertical velocity fields in CTL, SUA, and SLC averaged over $t=$ $60-72,72-84$, and 84-96 h. The major vertical motions are mostly located in the northeastern or southeastern quadrants of the vortex, similar to the upper-level westerly winds. Thus, the asymmetries of the vertical motion and associated diabatic heating might play an important role in generating the upper-level asymmetric westerly flows. The diabatic heating in the northeastern quadrant of the vortex is associated with the upper-level outflows and divergent flows. In other words, the relatively large diabatic heating in the northeastern quadrant of the vortex generates anomalous southwesterly outflows around the vortex center at the upper-level. With the effect of Earth's vorticity, the northwesterly winds beyond the vortex core are dominant at the upper-level in the northeastern quadrant of the vortex as shown in Fig. 4. When the large-scale upper-level anticyclone is added into the CTL run, it increases the westerly wind asym- 
(a)CTL/60-72h
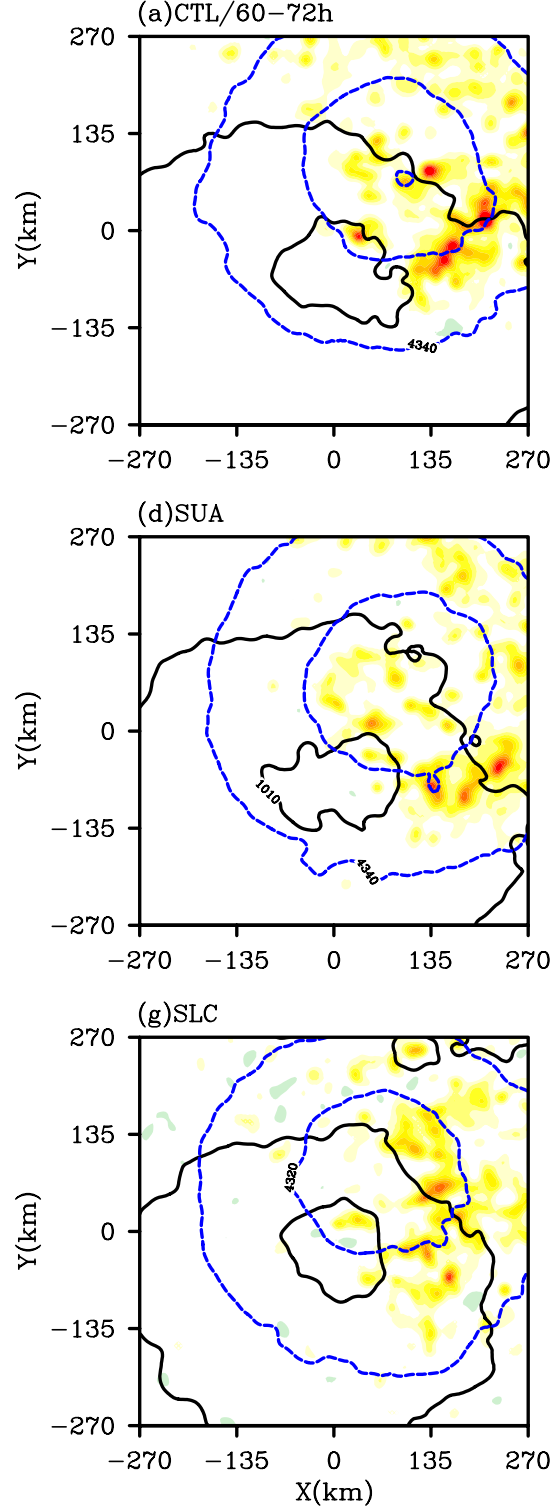

(b) $72-84 \mathrm{~h}$
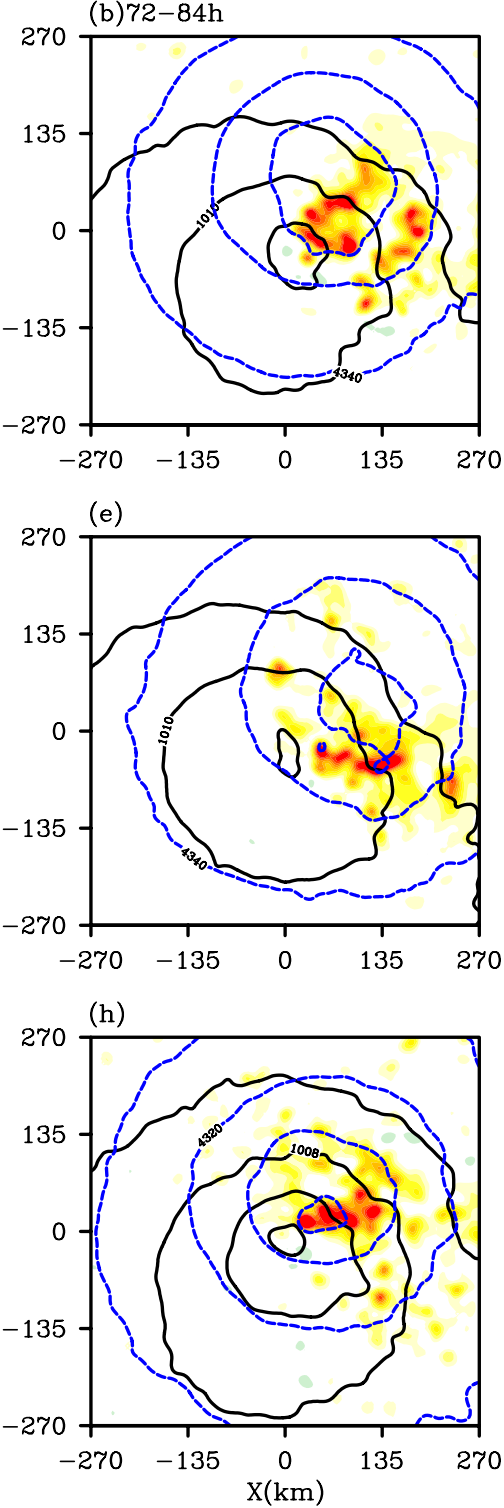
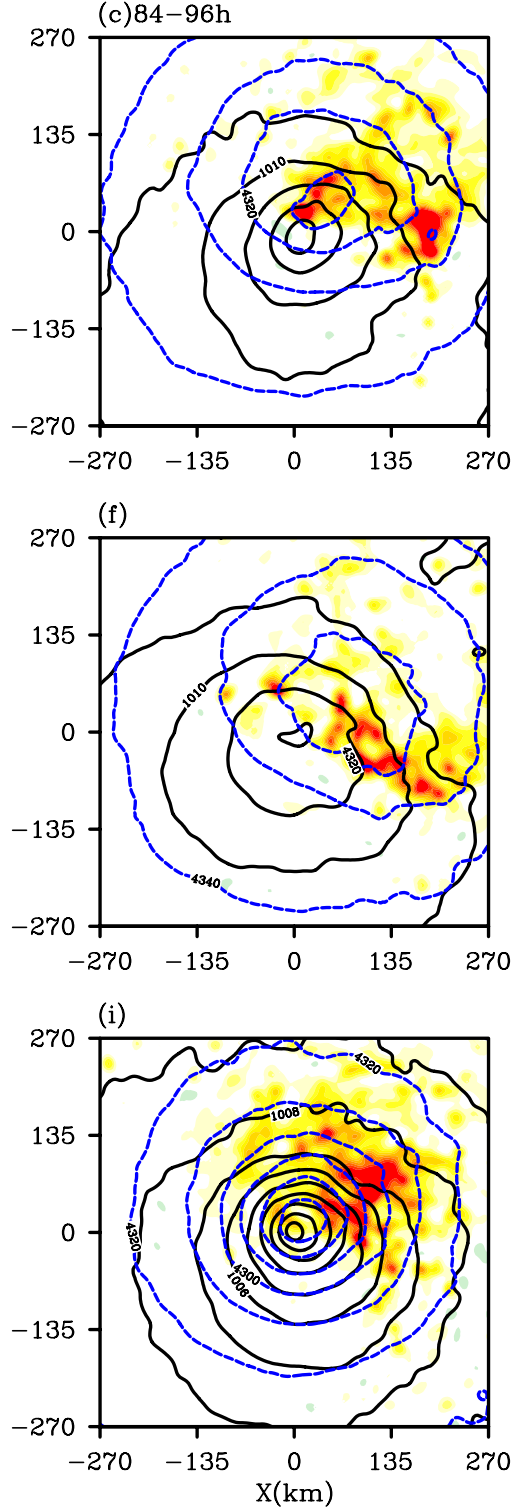
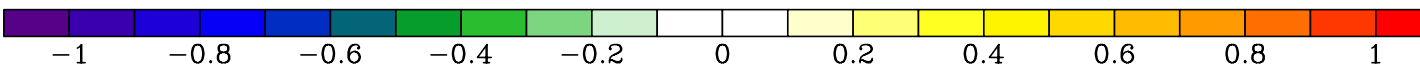

Fig. 7. The 600-hPa geopotential height (blue dashed contours), SLP (black solid contours), and 300-hPa vertical velocity fields (shading) in (a-c) CTL, (d-f) SUA, and (g-i) SLC averaged over $t=60-72 \mathrm{~h}(\mathrm{left}), 72-84 \mathrm{~h}$ (middle), and 84-96 h (right).

metry north of the vortex, resulting in a larger vertical westerly wind shear than that in CTL, as shown in Fig. 6. The processes above are similar to those proposed by Li et al. (2014). They suggested that the convection asymmetries and associated diabatic heating induced by the land-sea surface contrast play a critical role in generating upper-level asymmetric westerly flows. Moreover, due to the weakest inertial instability at the upper-level in SUA, induced by strong anticyclonic flows, the outflow jet extends over a greater horizontal distance at the upper-level than at the lower-level (Ge et al. 2010). The vertical wind shear in the simulation is different from the beta shear, which results from the height-dependent planetary vorticity advection (Wang and Holland 1996a, b; Ritchie and Frank 2007; Fang and Zhang 2012). 

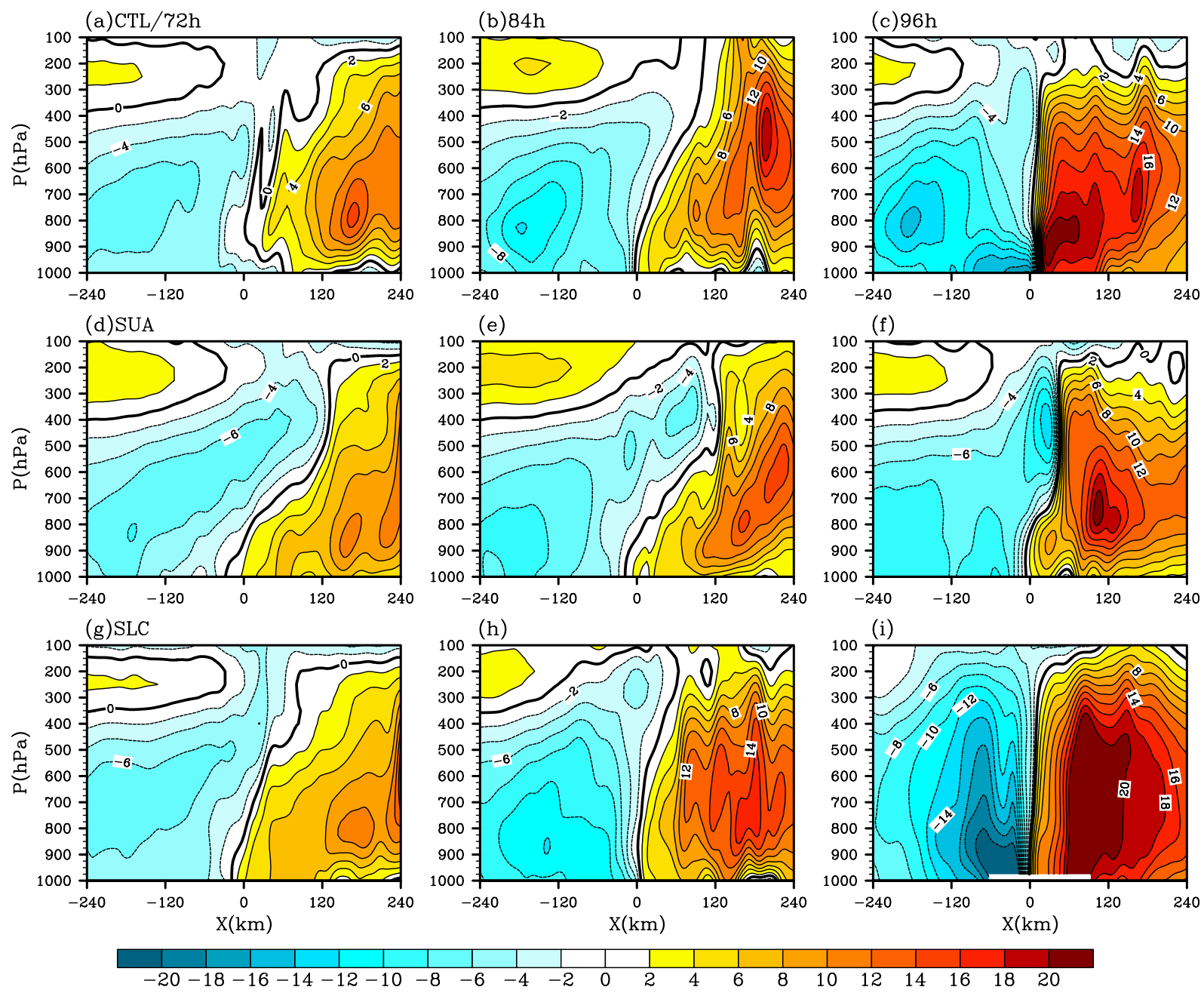

Fig. 8. The vertical zonal cross-sections of the meridional wind $\left(\mathrm{m} \mathrm{s}^{-1}\right)$ in $(\mathrm{a}-\mathrm{c}) \mathrm{CTL},(\mathrm{d}-\mathrm{f}) \mathrm{SUA}$, and (g-i) SLC at $t=72 \mathrm{~h}$ (left), $84 \mathrm{~h}$ (middle), and $96 \mathrm{~h}$ (right).

These studies mainly examined the beta shear's effect on a mature TC's intensity. Ritchie and Frank (2007) indicated that the beta shear is primarily associated with the structure of the initial vortex, which consists of a cyclone in the lower-level and an anticyclone in the upper-level. In the present study, the imposed large-scale anticyclonic circulation in the upper-level induces the vertical wind shear.

Previous studies have shown that vertical wind shear can lead to the development of a forced secondary circulation with an anomalous ascent on the downshear side and an anomalous descent on the upshear side (e.g., Zhang and Kieu 2006; Ge et al. 2013). These studies suggested that the ascending branch on the downshear side may reinforce itself through releasing latent heat by convection and enhance the secondary circulation. This enhanced secondary circulation could overcome the tilting induced by vertical wind shear and restore the vertical alignment, resulting in TC genesis (Ge et al. 2013). In contrast, some other studies suggested that a diabatically driven secondary circulation cannot maintain a mature TC's vertical alignment directly (Jones 2004; Reasor et al. 2004; Reasor and Eastin 2012). These researchers indicated that an inviscid damping mechanism intrinsic to a vortex's dry adiabatic dynamics is responsible for decreasing deviations from an upright state. To further examine how vertical wind shear makes a negative contribution to TC genesis, we investigate the vertical zonal cross-section of the meridional wind through the vortex center at $t=72,84$, and $96 \mathrm{~h}$ in CTL, SUA, and SLC (Fig. 8). At $t=72 \mathrm{~h}$, the vortices more 
(a)CTL

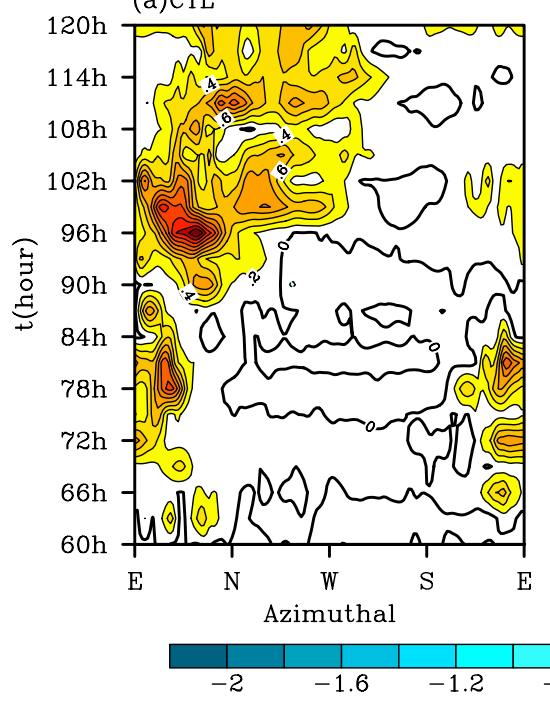

(b)SUA

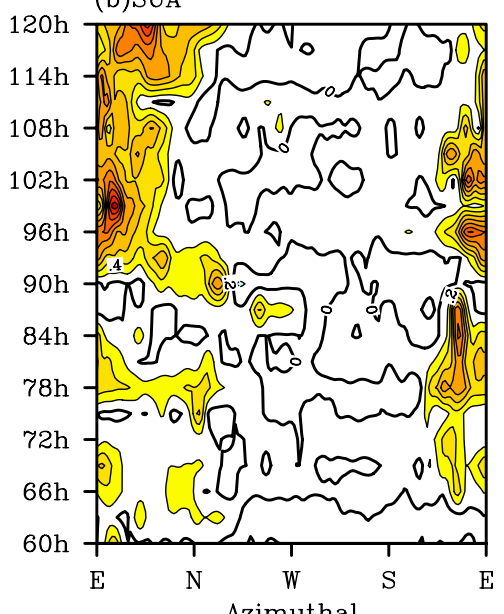

(c)SLC

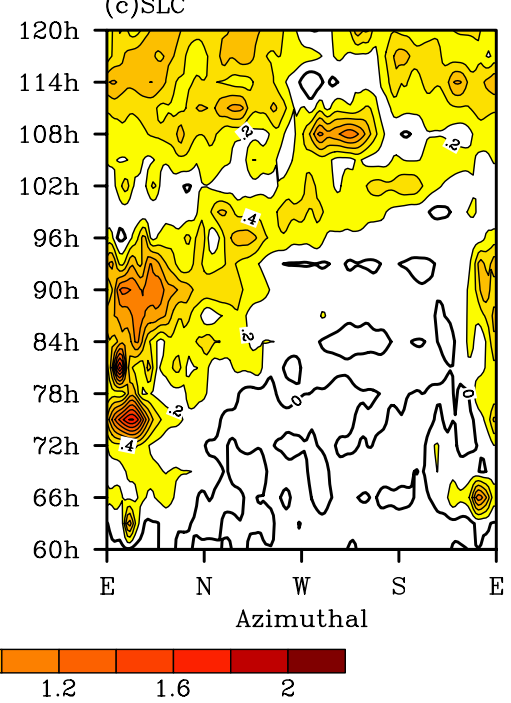

Fig. 9. The time-azimuthal cross-sections of the radial-mean $(0-150 \mathrm{~km})$ vertical motion $\left(\mathrm{m} \mathrm{s}^{-1}\right)$ at $300 \mathrm{hPa}$ for CTL, SUA, and SLC from $t=60 \mathrm{~h}$ to $t=120 \mathrm{~h}$.

or less tilt eastward in the vertical direction under the beta-induced westerly shear that results from the height-dependent advection of the planetary vorticity (Figs. 8a, d, g). The tilt induced by the beta-induced shear might play a role in the early development of asymmetric convection. This eastward tilt is the most remarkable in SUA due to the strongest vertical zonal wind shear (Figs. 8d, 6). Twelve hours later, the vertical tilt decreases and the vertical alignment of each vortex in CTL and SLC is gradually restored, with more evident vertical alignment in the latter (Figs. $8 \mathrm{~b}, \mathrm{~h})$. Accompanied by this vertical alignment, the vortices begin to intensify rapidly (Fig. 2). However, the vertical tilt persists in SUA during the following $12 \mathrm{~h}$ (Fig. 8e), indicating that the secondary circulation is not strong enough to restore the vertical alignment in SUA. At $t=96 \mathrm{~h}$, the vortices become vertically aligned in CTL and SLC (Figs. 8c, i). The meridional wind, however, is much stronger in SLC than in CTL. In SUA, the meridional wind of the vortex is still characterized by an eastward tilt with height and a zonal asymmetric structure at the middle-lower levels at $t=96 \mathrm{~h}$ (Fig. 8f); as a result, the vortex develops slowly in SUA (Fig. 2).

As discussed above, strong vertical wind shear can ventilate moisture and energy away from the TC core region, inhibiting TC development (Gray 1968). Figure 9 shows the time-azimuthal cross-sections of the radial-mean $(0-150 \mathrm{~km})$ vertical motion at 300 $\mathrm{hPa}$ for CTL, SUA, and SLC from $t=60 \mathrm{~h}$ to $t=$
$120 \mathrm{~h}$. The $300-\mathrm{hPa}$ level is the maximum vertical motion location. Before $t=90 \mathrm{~h}$, the dominant vertical motions in the three runs are located in the northeastern and southeastern quadrants of the vortex. Among the three runs, the extents of the azimuthal coverage of the vertical motions are the smallest in SUA, indicating that the SUA's larger vertical wind shear makes a negative contribution to the frequency of the convective cells. After $t=90 \mathrm{~h}$, convection starts to develop along the anti-clockwise direction of the vortex in CTL and SLC (Figs. 9a, c). In SLC, the vortex is almost entirely wrapped by deep convection at $t=102 \mathrm{~h}$, indicating that the vertical motion asymmetries and associated diabatic heating decrease remarkably (Fig. 9c). In contrast, the vertical movement is still confined largely to the northeast and southeast quadrants of the vortex in SUA.

Figure 10 further shows the vertical-radial crosssections of the azimuthal-mean diabatic heating averaged over $t=60-72,72-84$, and $84-96 \mathrm{~h}$ in the three runs. At $60-72 \mathrm{~h}$, the diabatic heating is generally similar among three runs (Figs. 10a, d, g). In the following $12 \mathrm{~h}$, the differences in diabatic heating become evident among the three experiments. The convection in SLC is the most vigorous, maximizing at $500 \mathrm{hPa}$ at a radius of approximately $30 \mathrm{~km}$ (Fig. 10h). The convection in CTL is maximized at a radius of $50 \mathrm{~km}$ at the same level but with a relatively weak magnitude (Fig. 10b). In contrast, the diabatic heating in SUA is the weakest at the vortex center (Fig. 10e), 

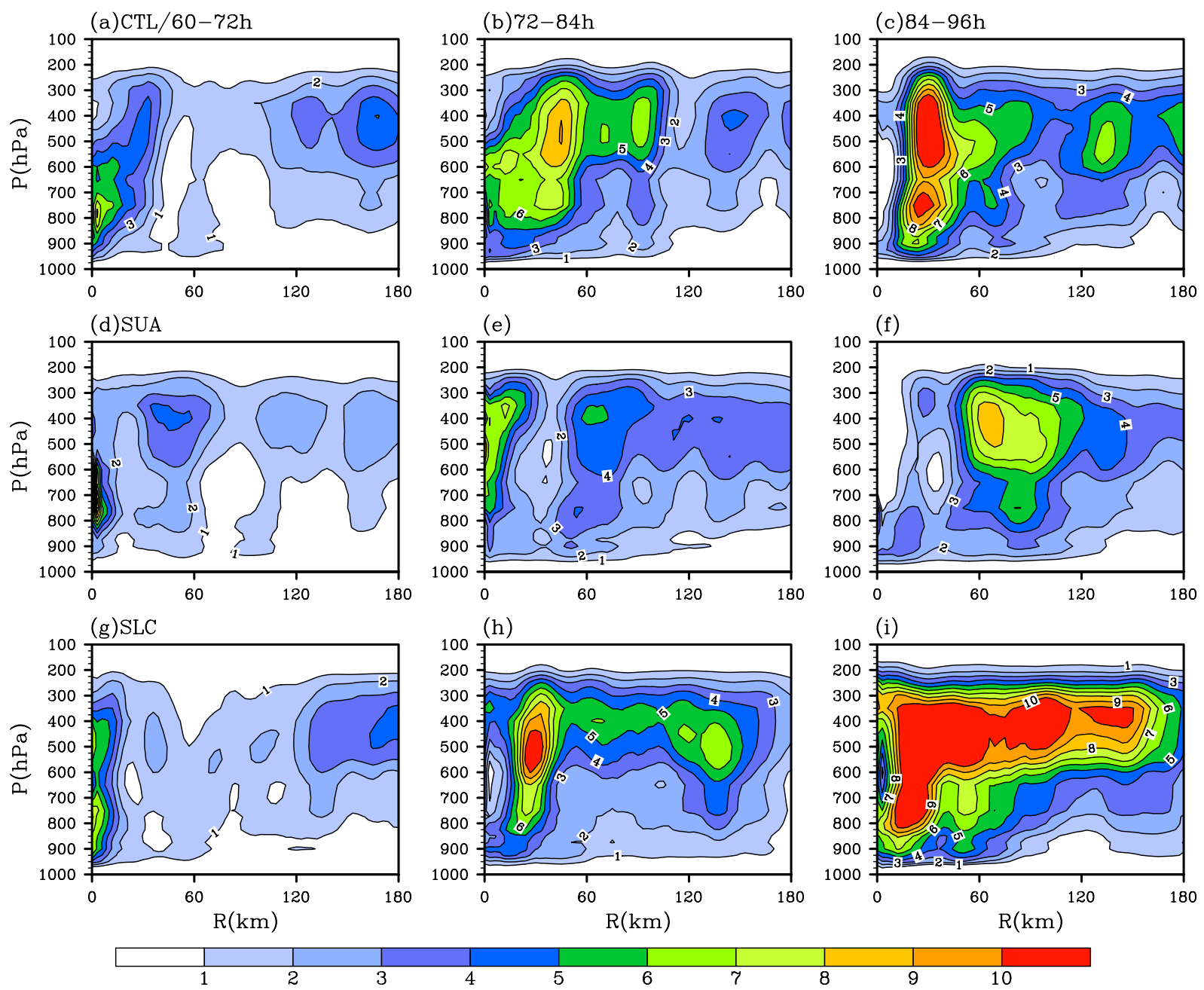

Fig. 10. The vertical-radial cross-sections of the azimuthal-mean diabatic heating $\left(10^{-4} \mathrm{~K} \mathrm{~s}^{-1}\right)$ in $(\mathrm{a}-\mathrm{c}) \mathrm{CTL}$, (d-f) SUA, and (g-i) SLC averaged over 60-72 h (left), 72-84 h (middle), and 84-96 h (right).

which may be due to the absence of a clear eye region and the tilt of the heating structure in the weak vortex. At $84-96 \mathrm{~h}$, greater diabatic heating is promoted in all three cases, with gradual restoration of the vortices' vertical alignment, as shown in Fig. 8. The heating structure in SLC (Fig. 10i) bears a characteristic convective precipitation regime (Mapes and Houze 1995), while the convective heating in CTL intensifies and contracts from a radius of $50 \mathrm{~km}$ to $20 \mathrm{~km}$ (Figs. $10 \mathrm{~b}, \mathrm{c})$. In contrast, the heat in SUA has a relatively larger size, indicating that the TC is characterized by a less contracted vortex (Fig. 10f). The results shown in Figs. 9 and 10 suggest that a strong vertical zonal wind shear can induce slow vortex development by ventilating energy away from the inner core during the early stage of TC genesis.

Two groups of additional sensitivity experiments support the physical mechanisms that we propose. The first group of experiments is similar to the SUA case, except the initial specific humidity is decreased by $50 \%$ to examine the impact of the moisture. This experiment is called SUAdry50. As expected, vortex development is slower in SUAdry50 than in SUA and CTL due to the decrease in moisture (Fig. 11). Furthermore, we compare the surface latent and sensible heat fluxes and the vertical structure of the vortex between SUA and SUAdry50. The asymmetric surface heat fluxes in SUAdry50 appear at $t=72 \mathrm{~h}$ and then intensify at $t=84 \mathrm{~h}$ and $t=96 \mathrm{~h}$ (Figs. 12a-c). The vortex does not show an obvious tilt at $t=72 \mathrm{~h}$ in SUAdry50 


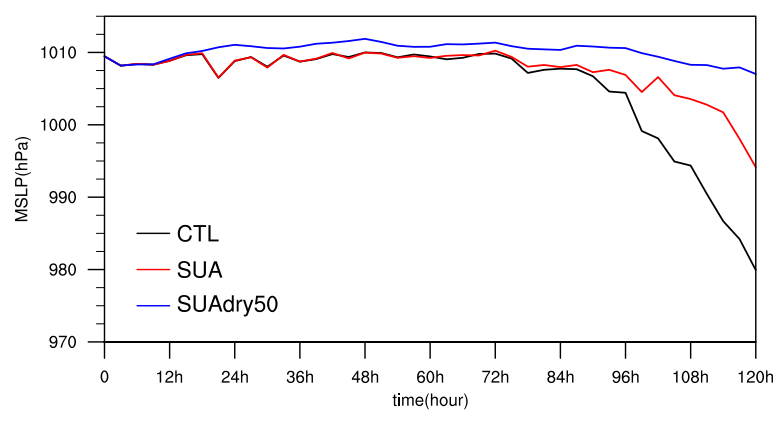

Fig. 11. The time evolutions of the MSLP $(\mathrm{hPa})$ in three experiments: CTL (black), SUA (red), and SUAdry50 (blue). The abscissa represents time (h), and the ordinate corresponds to the intensity of the MSLP.
(Fig. 12d). The vortex has a similar vertical tilt at $t=$ $60 \mathrm{~h}$ as at $t=72 \mathrm{~h}$ (figure not shown). With increased asymmetric surface heat fluxes, the eastward tilt in SUAdry50 increases remarkably after $t=84 \mathrm{~h}$ (Figs. $12 \mathrm{e}, \mathrm{f})$. Due to the decreased moisture content in the atmosphere, convection development and vertical tilting are delayed in SUAdry50 compared to SUA (Figs. 8,12 ). The comparison between SUA and SUAdry50 indicates that the vertical wind shear and vertical tilt do not develop earlier than the asymmetry of surface heat fluxes. The SUAdry50 sensitivity experiment supports the hypothesis that the vertical tilt of the vortex is induced by the asymmetries of the surface fluxes and associated diabatic heating.

The second group of experiments is similar to CTL and SUA, except that these experiments are conducted on an $\mathrm{f}$ plane at $15^{\circ} \mathrm{N}$; thus, they are called CTL $\mathrm{f}$ and SUA_f, respectively. The f plane eliminates the beta gyres, and the anticyclone in the upper-level is well maintained (figure not shown). Figure 13 shows that the vortex development in SUA $f$ is similar to the
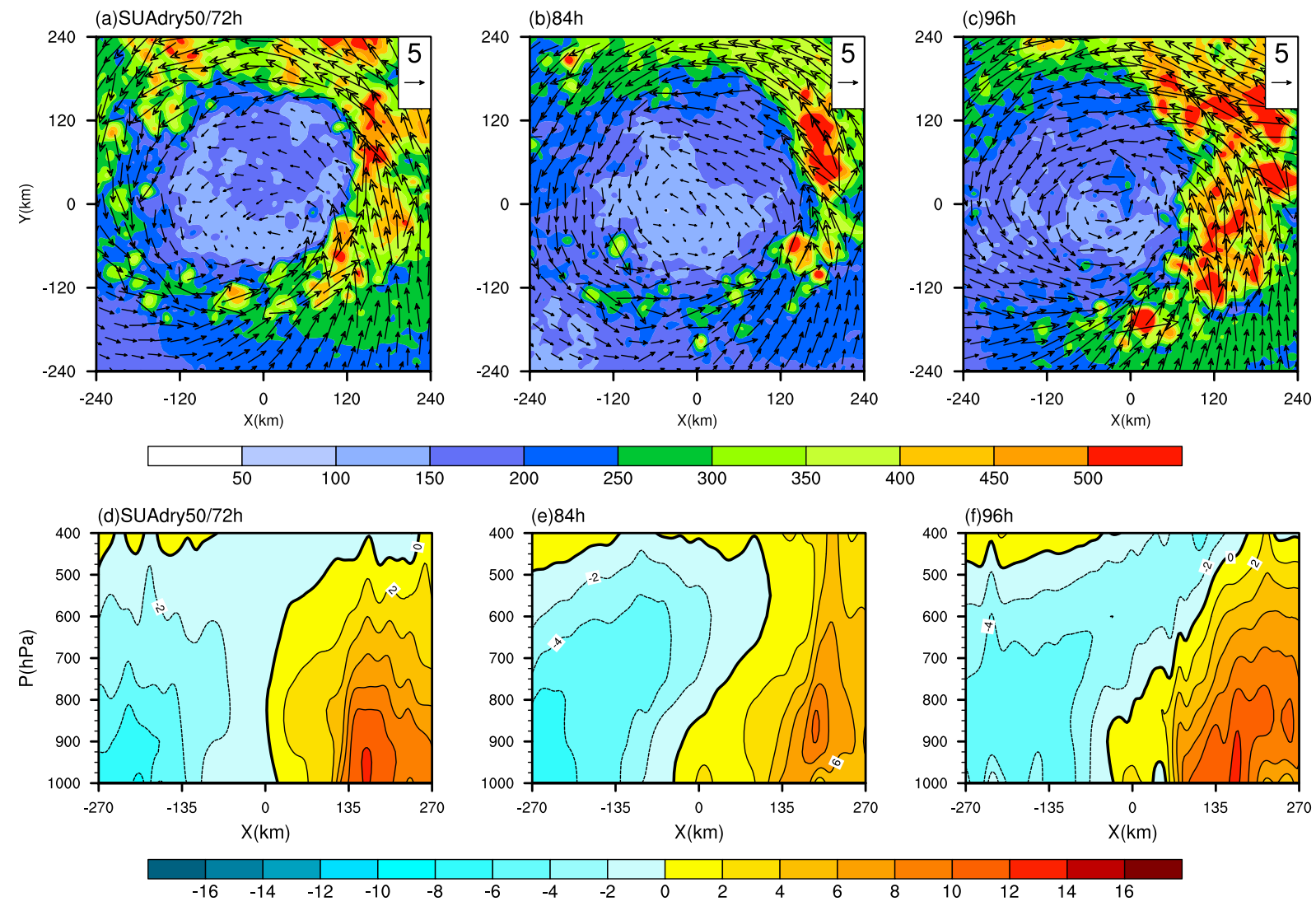

Fig. 12. The surface heat fluxes (unit: $\mathrm{W} \mathrm{m}^{-1}$ ) and $10-\mathrm{m}$ winds at (a) $t=72 \mathrm{~h}$, (b) $t=84 \mathrm{~h}$ and (c) $t=96 \mathrm{~h}$ in SUAdry50. $(\mathrm{d}-\mathrm{f})$ The same as in $(\mathrm{a}-\mathrm{c})$ except for the vertical zonal cross-sections of the meridional wind $\left(\mathrm{m} \mathrm{s}^{-1}\right)$. 
vortex in CTL_f, indicating that the well-organized upper-level anticyclone does not detrimentally affect tropical cyclogenesis. Through a comparison with the simulation results on the beta plane, we conclude that the establishment and development of the beta gyre, and the evolution and deformation of the upper-level anticyclonic circulation on the beta plane, result in a large vertical wind shear, which is unfavorable to tropical cyclogenesis. We will investigate the mechanisms by which the vortices in SUA_f and CTL_f have similar genesis times in future work.

\subsection{Lower-level cyclonic circulation}

As Fig. 2 shows, the modeling results indicate that the vortex has a large intensification rate under the lower-level cyclonic circulation. Thus, to examine how the lower-level cyclonic circulation makes a positive contribution to TC genesis, we first investigate the time evolutions of the area-averaged tangential wind, surface heat flux, relative humidity, and diabatic heating from $t=48 \mathrm{~h}$ to $t=96 \mathrm{~h}$ in CTL, SUA and SLC (Fig. 14). The vortex's superposition with the large-scale cyclonic circulation at the lower-level enhance the tangential wind in the core (Fig. 14b). These conditions induce greater surface heat fluxes (including both sensible and latent heat fluxes) in SLC than in CTL and SUA (Fig. 14c), leading to the upward extension of high humidity. As a result, the vertically averaged magnitude of relative humidity is greater in SLC than in CTL and SUA (Fig. 14c), which is favorable for the development of convection reflected by the vertically integrated diabatic heating (Fig. 14d). As shown in Fig. 9, the extent of the azimuthal coverage of strong vertical motion is the greatest in SLC, reflecting the occurrence of more convective bursts inside or near the maximum wind radius.

Previous studies showed that convective cells could experience progressive organization and aggregation toward the vortex center (Ge et al. 2013). Schecter and Dubin (1999) showed that vorticity anomalies, generated by small convective cells, could segregate under the ambient radial vorticity gradient's influence. Positive vorticity can move up, and negative vorticity can move down along the ambient vorticity gradient, resulting in the separation of positive and negative vorticities. Figure 15 shows the horizontal distribution of the relative vorticity for the small-scale system and large-scale system in CTL and SLC from $t=78 \mathrm{~h}$ to $t=108 \mathrm{~h}$ at an interval of $6 \mathrm{~h}$ by using the Fourier spatial filtering technique. Compared with CTL, the positive convectively generated vorticity anomalies have a faster build-up in SLC at $t=84 \mathrm{~h}$ (Figs. 15b, h).

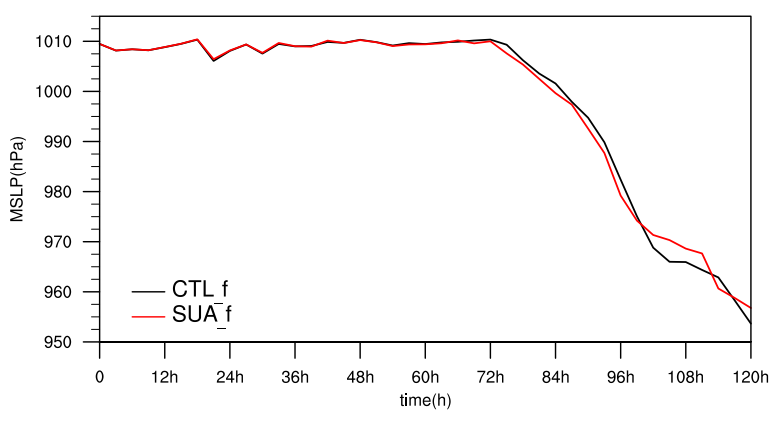

Fig. 13. The time evolutions of the MSLP $(\mathrm{hPa})$ in two experiments, CTL_f (black) and SUA_f(red), on an $\mathrm{f}$ plane at $15^{\circ} \mathrm{N}$. The abscissa represents time (h), and the ordinate corresponds to the intensity.

Subsequently, more small-scale vorticity anomalies aggregate toward the center region of the vortex in SLC (Figs. 15d-f, j-1). Ge et al. (2015) suggested that a larger ambient vorticity gradient is more favorable for a quicker segregation process. Figure 16 shows the radial profiles of the azimuthal-mean relative vorticity and the related vorticity gradient $(-d($ Vor $) / d R$; Vor is relative vorticity and $R$ is the radial distance from the $\mathrm{TC}$ center) near the TC center during the early stage of TC genesis. Consistent with the earliest TC genesis, the relative vorticity and the radial vorticity gradient are the largest in SLC among the three cases, which leads to a quicker TC genesis.

As an indicator of the potential for TC development, the Okubo-Weiss (OW) parameter is examined to measure the effect of horizontal flow deformation. At the middle level, large deformed flows can facilitate penetration of surrounding dry air into the core of a vortex, suppressing TC development (Dunkerton et al. 2009; Raymond et al. 2011; Ge et al. 2013). This process may inhibit the increases in moisture and convection necessary for the lower-level vortex spinup (Nolan 2007). Following Raymond et al. (2011), the normalized OW parameter is

$$
\mathrm{OW}=\frac{\varsigma^{2}-\sigma_{1}^{2}-\sigma_{2}^{2}}{\varsigma^{2}+\sigma_{1}^{2}+\sigma_{2}^{2}}
$$

where

$$
\varsigma=\frac{\partial v}{\partial x}-\frac{\partial u}{\partial y}, \sigma_{1}=\frac{\partial v}{\partial x}+\frac{\partial u}{\partial y}, \sigma_{2}=\frac{\partial u}{\partial x}-\frac{\partial v}{\partial y} .
$$

The above parameter is expressed in the form of the 

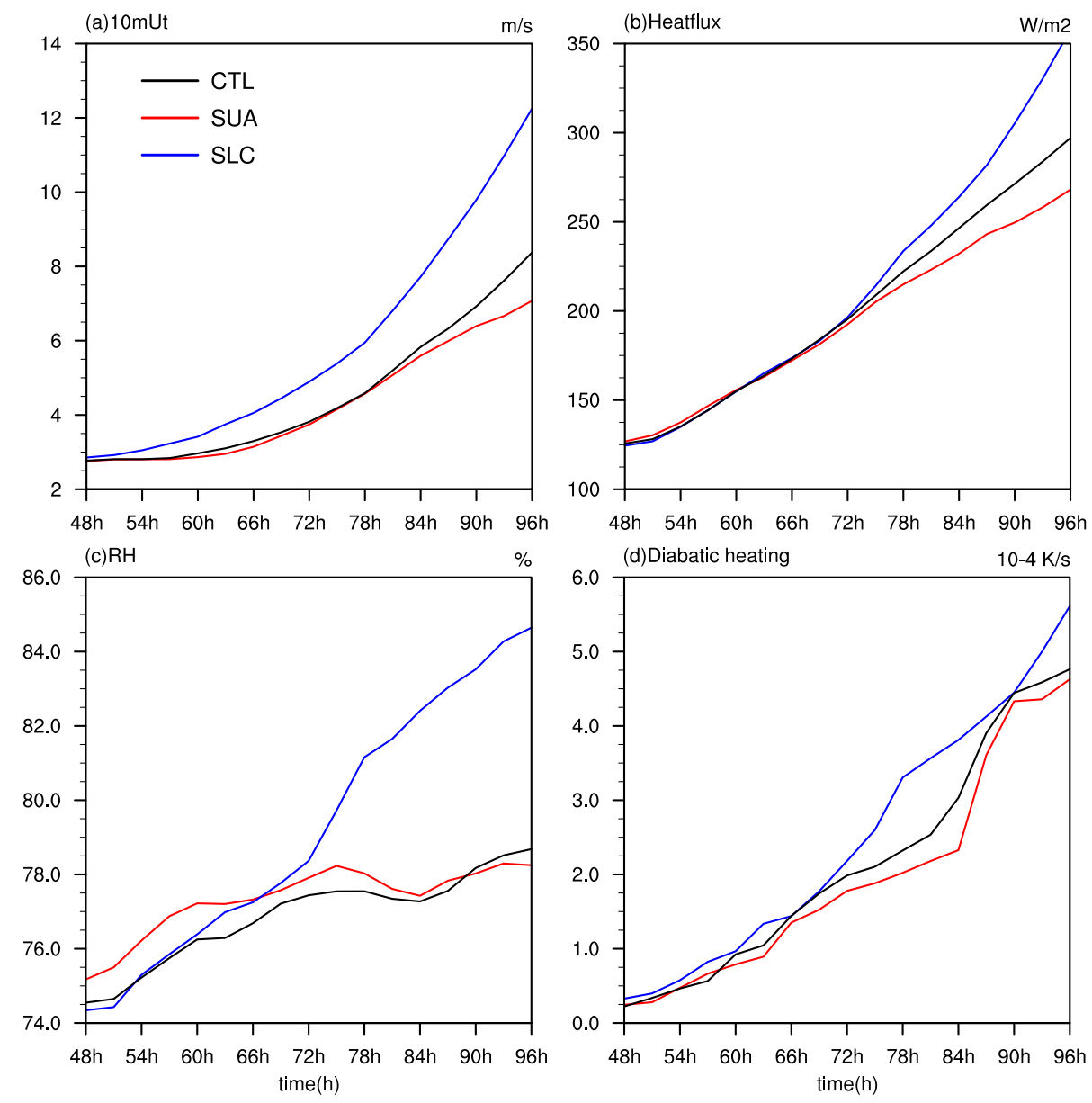

Fig. 14. The time evolutions (24-h running mean) of the (a) radial-mean $(0-180 \mathrm{~km})$ tangential wind $\left(\mathrm{m} \mathrm{s}^{-1}\right)$ at $10 \mathrm{~m}$, (b) radial-mean $(0-360 \mathrm{~km})$ surface heat flux $\left(\mathrm{W} \mathrm{m}^{-2}\right)$, (c) radial-mean $(0-180 \mathrm{~km})$ and vertically averaged (1000$300 \mathrm{hPa}$ ) relative humidity $(\%)$, and $(\mathrm{d})$ vertically averaged $(1000-200 \mathrm{hPa})$ diabatic heating $\left(10^{-4} \mathrm{~K} \mathrm{~s}^{-1}\right)$ in CTL (black), SUA (red), and SLC (blue) from $t=48 \mathrm{~h}$ to $t=96 \mathrm{~h}$.

square of the relative vorticity minus the squares of the two strain rate components. The parameter equals 1 when the flow is entirely rotational and -1 when the flow is strained. Generally, the maxima of the OW parameter are around the inner core of the vortex. Figure 17 depicts the evolution of the area-averaged $(60 \mathrm{~km} \times 60 \mathrm{~km})$ OW parameter in vertical-time cross-sections from $t=72 \mathrm{~h}$ to $t=120 \mathrm{~h}$ following the vortex center in the three experiments. The value of the OW parameter in SLC is much higher and more positive in the middle troposphere than in the other two experiments. Thus, rotational flows dominate over strained flows in SLC, which inhibit dry air entrainment into the vortex region core (Raymond et al. 2011).

Note that $\mathrm{Xu}$ et al. (2016) found that a vortex does not experience a quicker genesis when a TC is embedded into a monsoon gyre. They demonstrated that vortex superposition with a large-scale monsoon gyre produces a vortex with a larger outer size, which is not conducive to rapid vortex development (Xu and Wang 2018). However, in our study, a vortex superposition with a large-scale cyclonic circulation at the lowerlevel does not lead to a noticeable increase in the maximum wind radius, except for a salient rise in the tangential wind near and outside the maximum wind radius (Fig. 18). Our simulation results show that increasing the tangential wind near and outside the maximum wind radius can result in higher surface heat fluxes in SLC, which is favorable for convection development in the core of the vortex (Fig. 14). Thus, the large-scale cyclonic circulation's positive contri- 
(a) $78 \mathrm{~h} / \mathrm{CTL}$
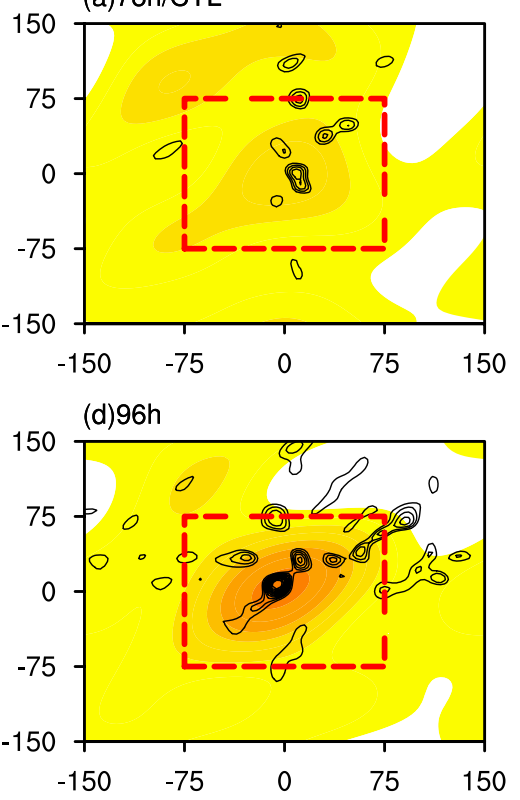

(g) $78 \mathrm{~h} / \mathrm{SLC}$

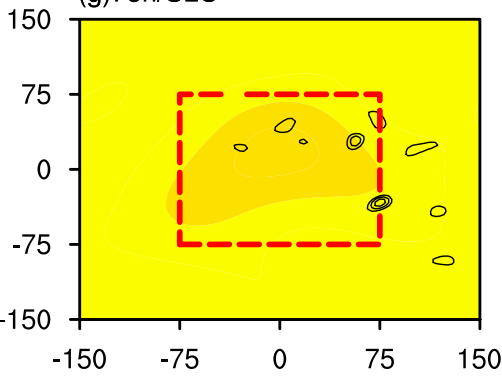

$\begin{array}{lllll}-150 & -75 & 0 & 75 & 150\end{array}$

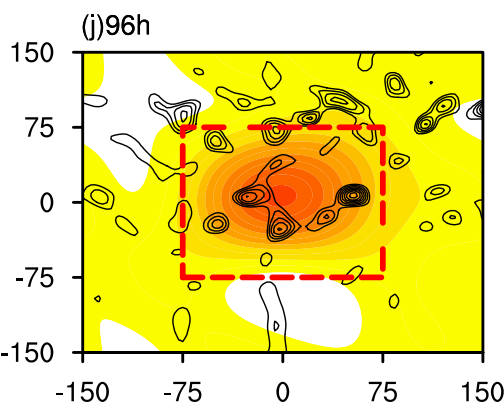

(b) $84 \mathrm{~h}$

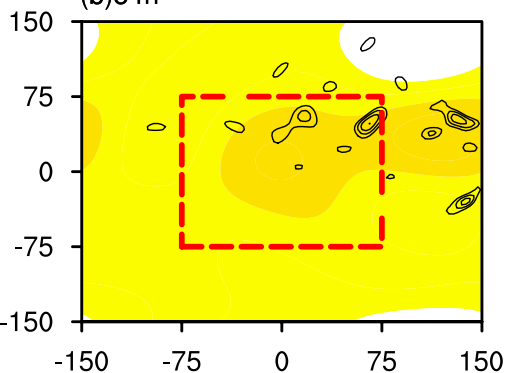

(e) $102 \mathrm{~h}$

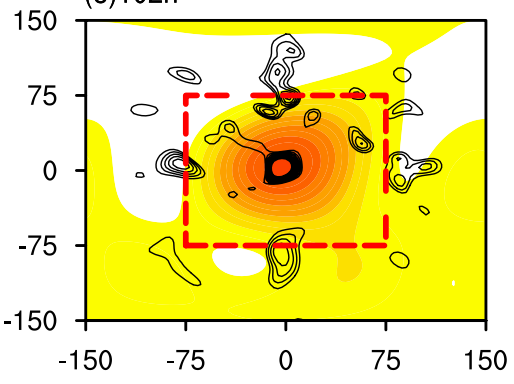

(h) $84 \mathrm{~h}$

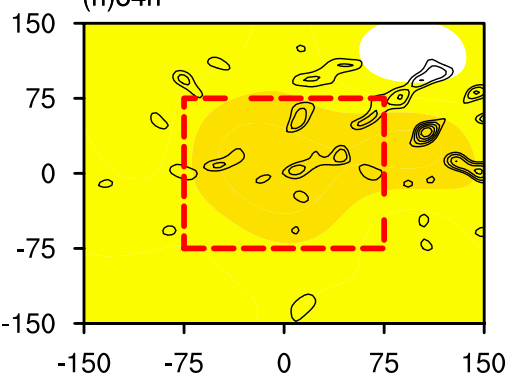

(k) $102 \mathrm{~h}$

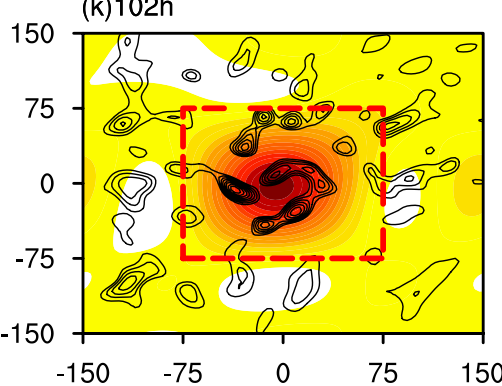

(c) $90 \mathrm{~h}$
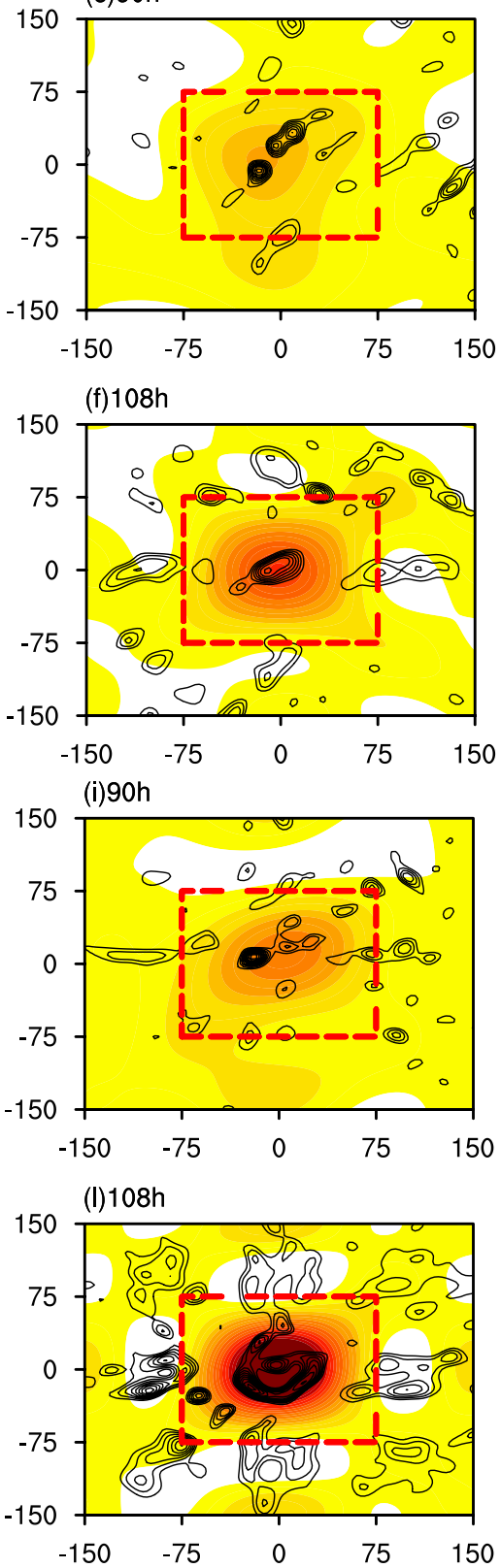

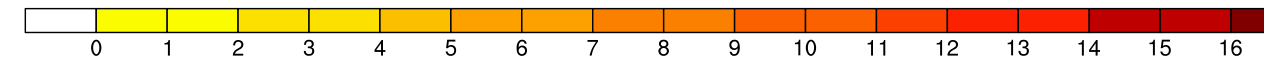

Fig. 15. The horizontal distributions of the relative vorticity for the small-scale system (contours, beginning from $3 \times 10^{-5} \mathrm{~s}^{-1}$ at an interval of $1 \times 10^{-5} \mathrm{~s}^{-1}$ ) and the large-scale system (shading, at an interval of $1 \times 10^{-5} \mathrm{~s}^{-1}$ ) in the $(\mathrm{a}-\mathrm{f}) \mathrm{CTL}$ and $(\mathrm{g}-1) \mathrm{SLC}$ cases from $t=78 \mathrm{~h}$ to $t=108 \mathrm{~h}$ at an interval of $6 \mathrm{~h}$. The red box denotes the central region of the vortex. 

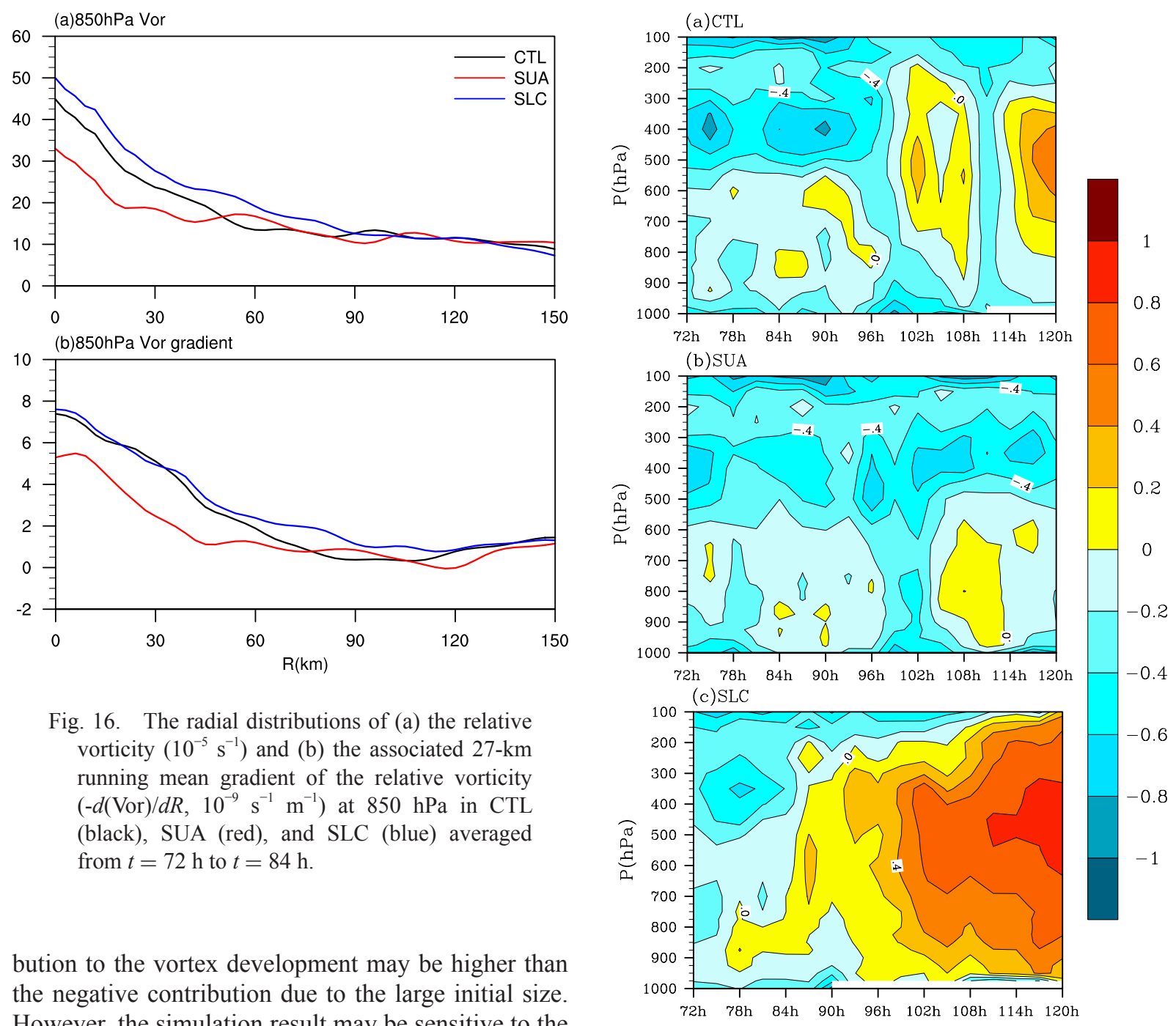

bution to the vortex development may be higher than the negative contribution due to the large initial size. However, the simulation result may be sensitive to the size of the large-scale cyclonic circulation, which will be investigated further in future work.

\subsection{Sensitivity experiments}

The third group of additional experiments is designed to examine the vortex development's sensitivity to the upper-level anticyclonic circulation structure (see Table 1). The four experiments in this group are the same as SUA except for differences in the vertical height, radius, and intensity of the maximum tangential wind of the upper-level anticyclonic circulation. Only one parameter of the maximum tangential wind is modified in each additional experiment relative to the parameters in SUA. In the first and second experiments (SUA_P250 and SUA_P100, respectively), the maximum upper-level anticyclonic circulation is set at $250 \mathrm{hPa}$ and $100 \mathrm{hPa}$, respectively. In the third experiment (SUA_R400), the initial maximum tangential

Fig. 17. The vertical-time cross-sections of the area-averaged OW parameter $(60 \mathrm{~km} \times 60 \mathrm{~km})$ from $t=72 \mathrm{~h}$ to $t=120 \mathrm{~h}$ in (a) CTL, (b) SUA and (c) SLC.

wind of the upper-level anticyclonic circulation is located at a radius of $400 \mathrm{~km}$. In the fourth experiment (SUA_V16), the initial maximum tangential wind of the upper-level anticyclonic circulation is set to 16 $\mathrm{m} \mathrm{s}^{-1}$.

Figure 19 shows the time evolutions of the MSLP in CTL, SUA, SUA_P250, SUA_P100, SUA_R400, and SUA_V16. The vortex development, influenced by the upper-level anticyclonic circulation, is not highly sensitive to the vertical height, radius, and magnitude of the maximum tangential wind of the upper-level anticyclonic circulation. Compared with that in CTL, 


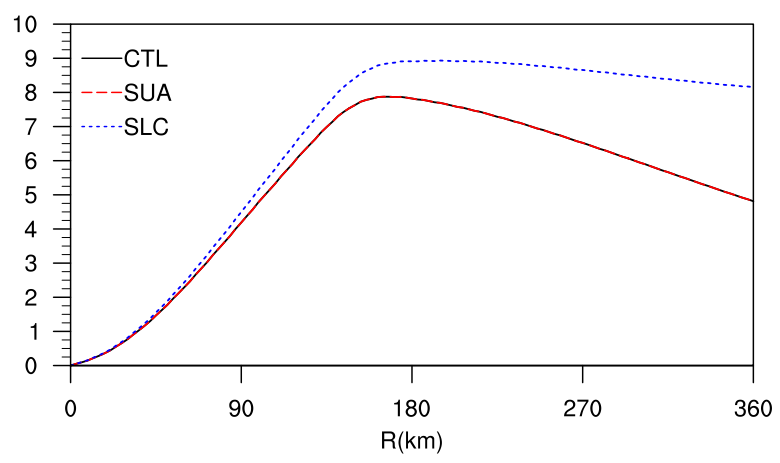

Fig. 18. The radial distributions of the azimuthalmean tangential wind of the vortex at the surface $\left(\mathrm{m} \mathrm{s}^{-1}\right.$ ) in CTL (black), SUA (red), and SLC (blue) at the initial time.

the upper-level anticyclonic circulations in the additional experiments have a consistently negative effect on the rapid development of the vortex. The wind field evolutions at $150 \mathrm{hPa}$ in SUA_P250, SUA_R400, and SUA V16 (shown in Fig. 20) are also examined and compared with the evolution in SUA. At the initial time, the winds at $150 \mathrm{hPa}$ are very weak in SUA P250 (Fig. 20a), whereas there are intense anticyclonic circulations in SUA_R400 and SUA_V16, with stronger winds covering broader extents in the latter (Figs. 20d, g). At $t=72 \mathrm{~h}$, the westerly wind development to the north-northeast in these three experiments is associated with the lower-level beta gyre and the asymmetries of the vertical motion and diabatic heating, as discussed in Section 3.2. At $t=120 \mathrm{~h}$, the westerly winds poleward of the vortex center intensify and dominate on the northeastern side of the vortex center in these three runs (Figs. 20c, f, i). The westerly wind evolutions in all three experiments are similar to those in SUA (Figs. 20, 4d-f). As a result, a relatively strong vertical wind shear is induced, which slows down the development of the vortex, as discussed in Section 3.2. The simulation results indicate that the upper-level anticyclonic circulation makes a negative contribution to the vortex development compared with CTL, regardless of the vertical height, radius, and magnitude of the maximum tangential wind of the upper-level anticyclonic circulation. This conclusion agrees with the finding of $\mathrm{Xu}$ et al. (2016). They showed that an upper-level circulation associated with a monsoon gyre is not conducive to vortex development.

Additional sensitivity experiments examine the statistical significance of the simulation results related
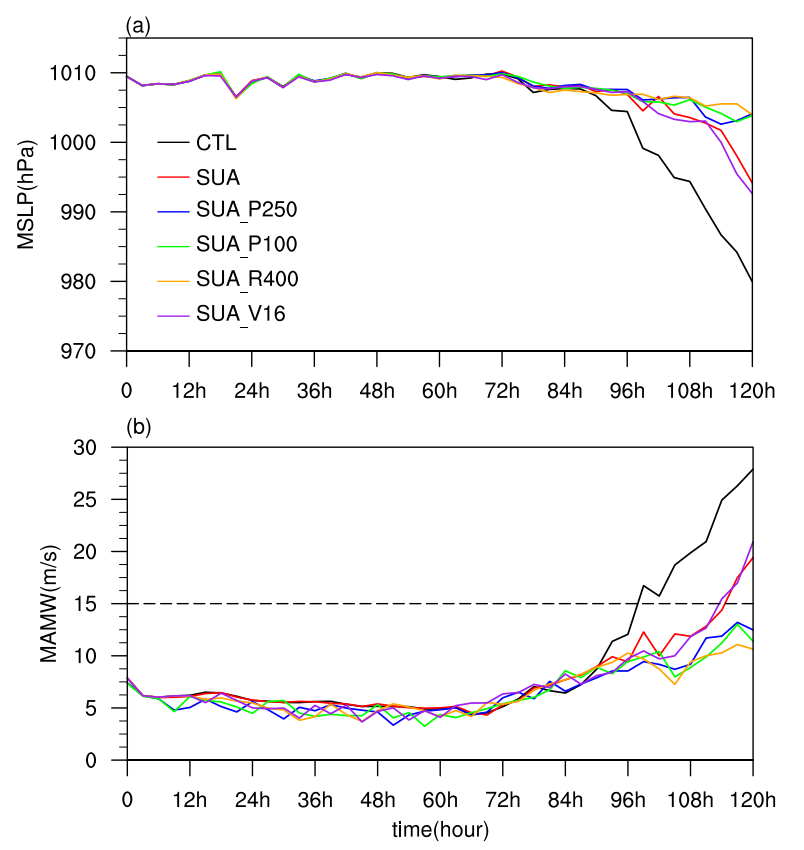

Fig. 19. The time evolutions of the (a) MSLP (hPa) and (b) MAMW ( $\mathrm{m} \mathrm{s}^{-1}$ ) in CTL (black), SUA (red), SUA_P250 (blue), SUA_P100 (green), SUA_R400 (orange), and SUA_V16 (purple). The abscissa represents the integration time (h), and the ordinate corresponds to the intensity. The dashed line in (b) denotes the TC genesis time when the MAMW speed exceeds $15 \mathrm{~m} \mathrm{~s}^{-1}$.

to the initial conditions in the CTL and SLC cases. Five three-dimensional random disturbances with the magnitude less than $10^{-2} \mathrm{~m} \mathrm{~s}^{-1}$ are added into the zonal wind fields in the CTL and SLC cases at the initial time, respectively. The black and red solid lines in Fig. 21 show averaged MSLP's time evolutions in the vortex in all the CTL and SLC experiments, respectively. As shown in Fig. 21, the simulation results are not so sensitive to the initial conditions, confirming that vortex development, initialized with the largescale lower-level cyclone, invariably occurs faster than the vortex development in the control simulation.

\section{Summary and discussion}

Previous studies on the effect of an upper-level circulation on vortex development were mainly focused on the intensity and structural changes of a mature TC, not on TC genesis. Some earlier studies suggested that both an upper-level anticyclonic circulation and a lower-level cyclonic circulation are necessary conditions for TC genesis. However, most of these 
(a)SUA_P250/0h

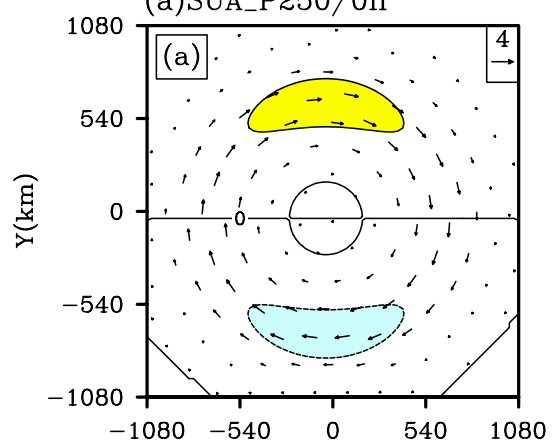

(d)SUA_R400

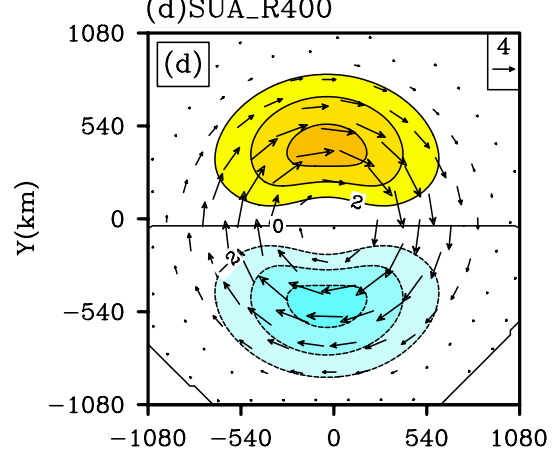

(g)SUA_V16

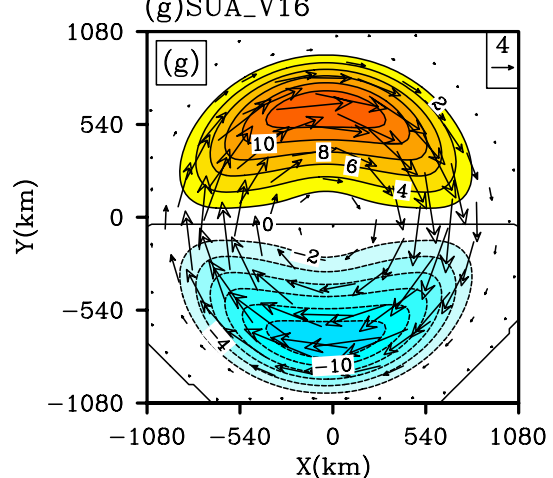

(b) $72 \mathrm{~h}$
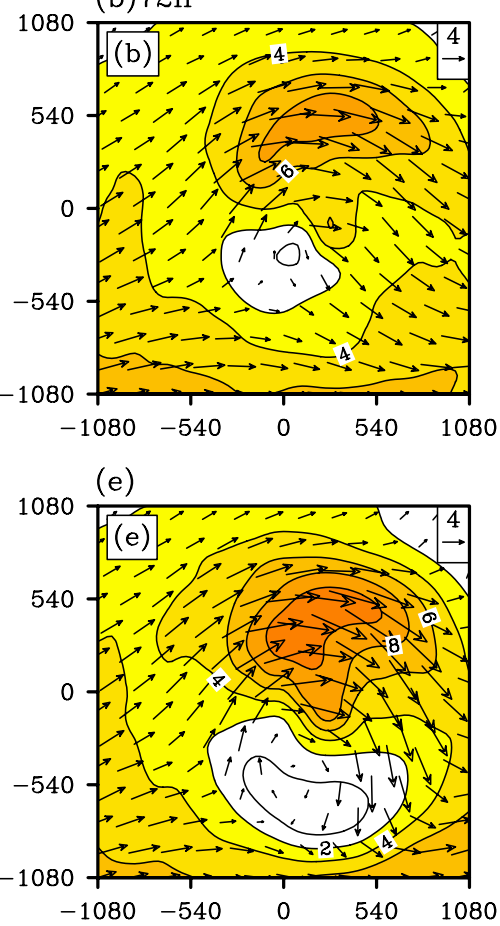

(h)

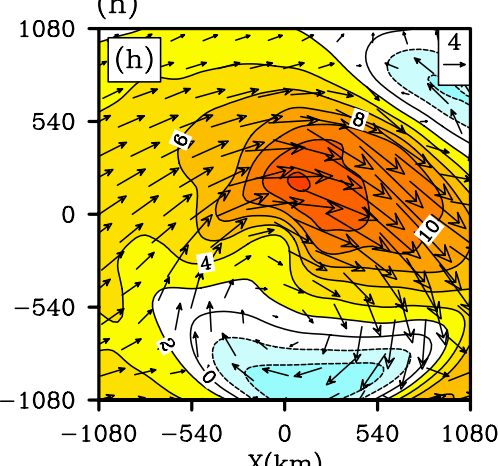

(c) $120 \mathrm{~h}$

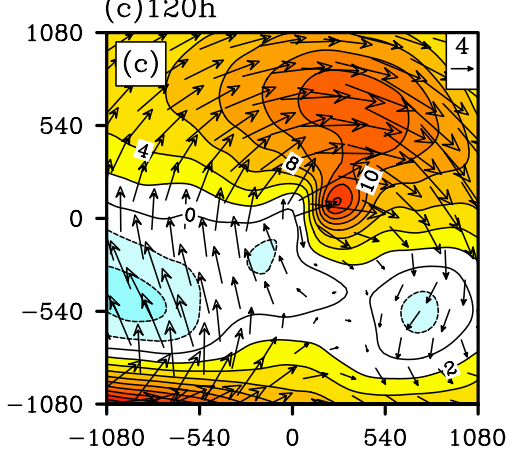

(f)

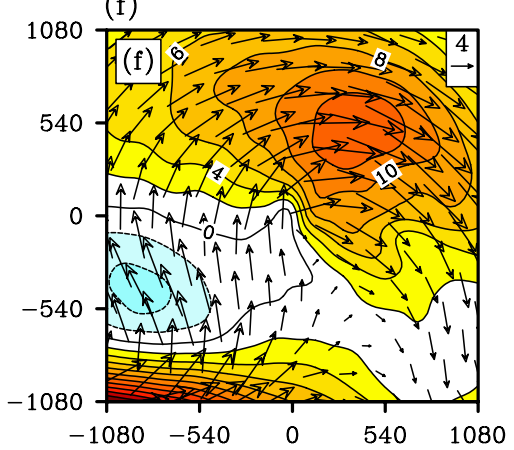

(i)

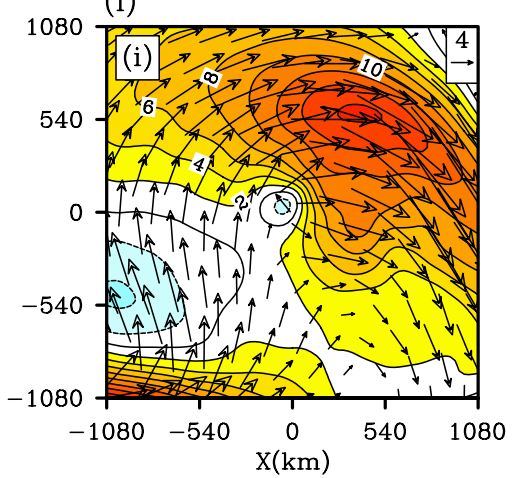

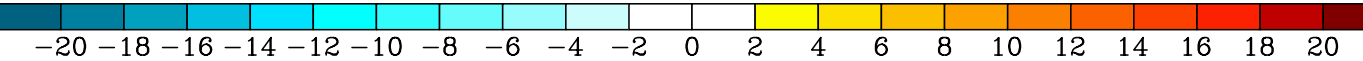

Fig. 20. The same as in Fig. 4 but in (a-c) SUA_P250, (d-f) SUA_R400, and (g-i) SUA_V16.

studies were confined to composite analyses based on observational data. This study presents further research to quantify the contributions of an upper-level anticyclonic circulation and a lower-level cyclonic circulation to TC genesis through idealized numerical experiments, using a mesoscale WRF model.

The model results show that, given a specified weak vortex, an upper-level anticyclonic circulation can result in the slower formation of a TC compared to CTL. The more gradual formation can be ascribed to the zonal wind structures at the upper-level, which are associated with the development of beta gyres in the lower-level cyclonic circulation and the resultant asymmetries of convection. A cyclonic-circulationinduced beta gyre leads to maximum winds located in the northeastern part of the vortex center at the lower-level. These winds induce intense surface heat fluxes and, thus, higher atmospheric humidity. The near-surface inflow, produced by friction, leads to ascending motion and increases the upward transport of moisture, facilitating more convective heating in the region of the maximum wind and heat fluxes. The dia- 


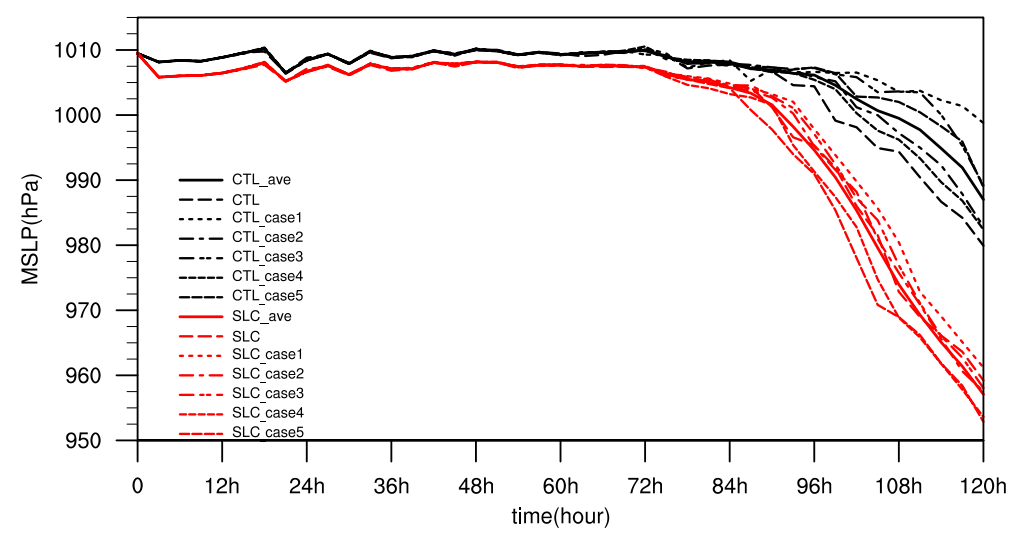

Fig. 21. The time evolutions of the MSLP (hPa) in the ensemble experiments of the CTL case (black) and SLC case (red). The abscissa represents time (h), and the ordinate corresponds to the intensity.

batic heating in the northeastern quadrant of the vortex generates anomalous northwesterly winds beyond the vortex core at the upper-level. The large-scale anticyclone at the upper-level increases the asymmetry of the westerly wind north of the vortex, resulting in a relatively large vertical westerly wind shear, which is an unfavorable factor for TC formation. As a result, the upper-level vortex shifts eastward from its original position, which is unsuitable for the vortex's vertical alignment. The forced secondary circulation has to take more time to help overcome the shear-induced drifting effect and restore the vertical alignment of the vortex. Therefore, upper-level anticyclonic circulation is indeed detrimental to TC formation.

In contrast, a lower-level cyclonic circulation can cause a TC to form more quickly due to the superposition of large-scale cyclonic vorticity and a vortex. The strong overlying wind induces large surface heat fluxes from the ocean and the convergence of moisture from the surrounding environment. In a moist environment, convection and diabatic heating can be strengthened. A higher initial absolute vorticity effectively enhances convection-circulation-moisture positive feedback. Moreover, a more significant OW parameter reveals the dominance of rotation over strain, which could inhibit dry environmental air penetration into the core region of the vortex at the middle level. These factors are indicators of the potential for vortex intensification.

In this study, we focus mainly on the separate roles of an upper-level anticyclonic circulation and a lowerlevel cyclonic circulation. In the future, we will carry out a series of sensitivity experiments to investigate the vortex development's sensitivity to large-scale circulations with different sizes and magnitudes. Meantime, the location of the upper-level anticyclonic circulation may vary horizontally depending on environmental factors. The study of MZ81 mentioned that a cloud cluster developing into a TC has an anticyclone displaced $\sim 3$ degrees latitude to the east of the system. Therefore, it is necessary to investigate the vortex development's sensitivity to the relative location of the upper-level anticyclonic circulation concerning the vortex core in future research.

\section{Acknowledgments}

The first author, Dr. Xi Cao, thanks Prof. Guanghua Chen, Prof. Chun-Chieh $\mathrm{Wu}$, and Dr. Xiping Zhang for their constructive suggestions, which helped improve the paper. We also appreciate the comments from the editor and three anonymous reviewers. The simulation data are generated using the WRF model (version 3.3.1), which are available upon request to the first author by email at caoxi09@mail.iap.ac.cn. This study was supported by the 2019 Open Research Program of the Shanghai Typhoon Institute (Grant TFJJ201901), the Open Grants of the State Key Laboratory of Severe Weather (Grant 2020LASW-B01) and the National Natural Science Foundation of China (Grant 41505048 and 41875057).

\section{References}

Cao, X., and R. G. Wu, 2018a: Simulations of development of tropical disturbances associated with the monsoon trough over the western North Pacific. Atmos. Sci. Lett., 19, e801, doi:10.1002/as1.801.

Cao, X., and R. G. Wu, 2018b: Comparison of different time scale contributions to tropical cyclone genesis over 
the western North Pacific in 2015 and 2016. J. Meteor. Soc. Japan, 96, 317-336.

Cao, X., P. Huang, G. H. Chen, and W. Chen, 2012: Modulation of western North Pacific tropical cyclone genesis by intraseasonal oscillation of ITCZ: A statistical analysis. Adv. Atmos. Sci., 29, 744-754.

Cao, X., T. Li, M. Peng, W. Chen, and G. H. Chen, 2014a: Effects of monsoon trough intraseasonal oscillation on tropical cyclogenesis over the western North Pacific. $J$. Atmos. Sci., 71, 4639-4660.

Cao, X., T. Li, M. Peng, W. Chen, and G. H. Chen, 2014b: Effects of monsoon trough interannual variation on tropical cyclogenesis over the western North Pacific. Geophys. Res. Lett., 41, 4332-4339.

Cao, X., G. H. Chen, T. Li, and F. M. Ren, 2016: Simulations of tropical cyclogenesis associated with different monsoon trough patterns over the western North Pacific. Meteor. Atmos. Phys., 128, 491-511.

Cao, X., R. G. Wu, and M. Y. Bi, 2018: Contributions of different time-scale variations to tropical cyclogenesis over the western North Pacific. J. Climate, 31, 31373153.

Cao, X., R. G. Wu, N. Wei, and Y. F. Dai, 2020: Location of the preferred region for tropical cyclogenesis in strong monsoon trough pattern over the western North Pacific. J. Meteor. Soc. Japan, 98, 637-654.

DeMaria, M., J. Kaplan, and J. J. Baik, 1993: Upper-level angular momentum fluxes and tropical cyclone intensity change. J. Atmos. Sci., 50, 1133-1147.

Dunkerton, T. J., M. T. Montgomery, and Z. Wang, 2009: Tropical cyclogenesis in a tropical wave critical layer: Easterly waves. Atmos. Chem. Phys., 9, 5587-5646.

Fang, J., and F. Zhang, 2012: Effect of beta shear on simulated tropical cyclones. Mon. Wea. Rev., 140, 33273346.

Feng, T., G. H. Chen, R. H. Huang, and X. Y. Shen, 2014: Large-scale circulation patterns favorable to tropical cyclogenesis over the western North Pacific and associated barotropic energy conversions. Int. J. Climatol., 34, 216-227.

Fiorino, M., and R. L. Elsberry, 1989: Some aspects of vortex structure related to tropical cyclone motion. $J$. Atmos. Sci., 46, 975-990.

Fu, B., M. S. Peng, T. Li, and D. E. Stevens, 2012: Developing versus nondeveloping disturbances for tropical cyclone formation. Part II: Western North Pacific. Mon. Wea. Rev., 140, 1067-1080.

Ge, X. Y., T. Li, and M. Peng, 2010: Cyclogenesis simulation of typhoon Prapiroon (2000) associated with Rossby wave energy dispersion. Mon. Wea. Rev., 138, 42-54.

Ge, X. Y., T. Li, and M. Peng, 2013: Effects of vertical shears and midlevel dry air on tropical cyclone developments. J. Atmos. Sci., 70, 3859-3875.

Ge, X., W. Xu, and S. W. Zhou, 2015: Sensitivity of tropical cyclone intensification on initial inner-core structure.
Adv. Atmos. Sci., 32, 1407-1418.

Gray, W. M., 1968: Global view of the origin of tropical disturbances and storms. Mon. Wea. Rev., 96, 669-700.

Gray, W. M., 1998: The formation of tropical cyclones. Meteor. Atmos. Phys., 67, 37-69.

Holland, G. J., 1983: Tropical cyclone motion: Environmental interaction plus a beta effect. J. Atmos. Sci., 40, 328-342.

Holland, G. J., 1997: The maximum potential intensity of tropical cyclones. J. Atmos. Sci., 54, 2519-2541.

Holland, G. J., and R. T. Merrill, 1984: On the dynamics of tropical cyclone structure changes. Quart. J. Roy. Meteor. Soc., 110, 723-745.

Jones, S. C., 2004: On the ability of dry tropical-cyclone-like vortices to withstand vertical shear. J. Atmos. Sci., 61, 114-119.

Kain, J. S., and J. M. Fritsch, 1993: Convective parameterization for mesoscale models: The Kain-Fritsch scheme. The Representation of Cumulus Convection in Numerical Models. Meteor. Monogr., No. 46, Kerry Emanuel, K. A., and D. J. Raymond(eds.), Amer. Meteor. Soc., 165-170.

Lee, C. S., K. K. Cheung, J. S. Hui, and R. L. Elsberry, 2008: Mesoscale features associated with tropical cyclone formations in the western North Pacific. Mon. Wea. Rev., 136, 2006-2022.

Leroux, M. D., M. Plu, D. Barbary, F. Roux, and P. Arbogast, 2013: Dynamical and physical processes leading to tropical cyclone intensification under upper-level trough forcing. J. Atmos. Sci., 70, 2547-2565.

Li, Y. B., K. K. W. Cheung, and J. C. L. Chan, 2014: Numerical study on the development of asymmetric convection and vertical wind shear during tropical cyclone landfall. Quart. J. Roy. Meteor. Soc., 140, 1866-1877.

Lin, Y. L., R. D. Farley, and H. D. Orville, 1983: Bulk parameterization of the snow field in a cloud model. $J$. Appl. Meteor, 22, 1065-1092.

Mapes, B. E., and R. A. Houze, Jr., 1995: Diabatic divergence profiles in western Pacific mesoscale convective systems. J. Atmos. Sci., 52, 1807-1828.

McBride, J. L., and R. Zehr, 1981: Observational analysis of tropical cyclone formation. Part II: Comparison of non-developing versus developing systems. J. Atmos. Sci., 38, 1132-1151.

Merrill, R. T., 1988: Environmental influences on hurricane intensification. J. Atmos. Sci., 45, 1678-1687.

Nolan, D. S., 2007: What is the trigger for tropical cyclogenesis? Aust. Meteor. Mag., 56, 241-266.

Rappin, E. D., M. C. Morgan, and G. J. Tripoli, 2011: The impact of outflow environment on tropical cyclone intensification and structure. J. Atmos. Sci., 68, 177194.

Raymond, D. J., S. L. Sessions, and C. Lopez Carrillo, 2011: Thermodynamics of tropical cyclogenesis in the northwest Pacific. J. Geophys. Res., 116, D18101, doi: 
10.1029/2011JD015624.

Reasor, P. D., and M. D. Eastin, 2012: Rapidly intensifying hurricane Guillermo, 1997: Part II: Resilience in shear. Mon. Wea. Rev., 140, 425-444.

Reasor, P. D., M. T. Montgomery, and L. D. Grasso, 2004: A new look at the problem of tropical cyclones in vertical shear flow: Vortex resiliency. J. Atmos. Sci., 61, 3-22.

Riemer, M., M. T. Montgomery, and M. E. Nicholls, 2010: A new paradigm for intensity modification of tropical cyclones: Thermodynamic impact of vertical wind shear on the inflow layer. Atmos. Chem. Phys., 10, 3163-3188.

Ritchie, E. A., and G. J. Holland, 1999: Large-scale patterns associated with tropical cyclogenesis in the western Pacific. Mon. Wea. Rev., 127, 2027-2043.

Ritchie, E. A., and W. M. Frank, 2007: Interactions between simulated tropical cyclones and an environment with a variable Coriolis parameter. Mon. Wea. Rev., 135, 1889-1905.

Sadler, J. C., 1976: A role of the tropical upper tropospheric trough in early season typhoon development. Mon. Wea. Rev., 104, 1266-1278.

Schecter, D. A., and D. H. Dubin, 1999: Vortex motion driven by a background vorticity gradient. Phys. Rev. Lett., 83, 2191-2194.

Schubert, W. H., and J. J. Hack, 1982: Inertial stability and tropical cyclone development. J. Atmos. Sci., 39, 1687-1697.

Skamarock, W. C., J. B. Klemp, J. Dudhia, D. O. Gill, D. M. Barker, M. G. Duda, X.-Y. Huang, W. Wang, and J. G. Powers, 2008: A description of the advanced research WRF version 3. NCAR Technical Note, NCAR/TN475+STR, 113 pp.

Wang, Y. Q., 1995: On an inverse balance equation in sigma- coordinates for model initialization. Mon. Wea. Rev, 123, 482-488.

Wang, Y. Q., 1998: On the bogusing of tropical cyclones in numerical models: The influence of vertical structure. Meteor. Atmos. Phys., 65, 153-170.

Wang, Y. Q., and G. J. Holland, 1996a: The beta drift of baroclinic vortices. Part I: Adiabatic vortices. J. Atmos. Sci., 53, 411-427.

Wang, Y. Q., and G. J. Holland, 1996b: The beta drift of baroclinic vortices. Part II: Diabatic vortices. J. Atmos. Sci., 53, 3737-3756.

Wu, C. C., and K. A. Emanuel, 1993: Interaction of a baroclinic vortex with background shear: Application to hurricane movement. J. Atmos. Sci., 50, 62-76.

Wu, C. C., and K. A. Emanuel, 1994: On hurricane outflow structure. J. Atmos. Sci., 51, 1995-2003.

Wu, L. G., H. J. Zong, and J. Liang, 2013: Observational analysis of tropical cyclone formation associated with monsoon gyres. J. Atmos. Sci., 70, 1023-1034.

Xu, J., and Y. Q. Wang, 2018: Effect of the initial vortex structure on intensification of a numerically simulated tropical cyclone. J. Meteor. Soc. Japan, 96, 111-126.

Xu, M. T., S. W. Zhou, and X. Y. Ge, 2016: An idealized simulation study of monsoon gyre on tropical cyclogenesis. Acta Meteor. Sin., 74, 733-743.

Yan, Z., X. Ge, M. Peng, and T. Li, 2019: Does monsoon gyre always favour tropical cyclone rapid intensification? Quart. J. Roy. Meteor. Soc., 145, 2685-2697.

Zehr, R. M., 1992: Tropical cyclogenesis in the western North Pacific. NOAA Tech. Rep. NESDIS 61, Department of Commerce, Washington DC, $181 \mathrm{pp}$.

Zhang, D. L., and C. Q. Kieu, 2006: Potential vorticity diagnosis of a simulated hurricane. Part II: Quasi-balanced contributions to forced secondary circulations. $J$. Atmos. Sci., 63, 2898-2914. 